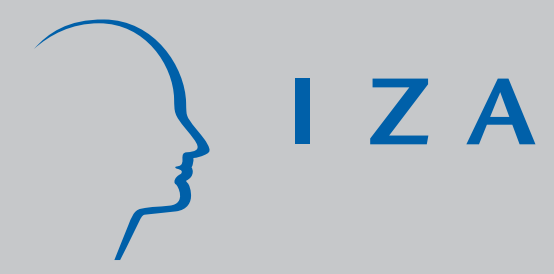

IZADP No. 4064

Have You Heard the News?

How Real-Life Expectations React to Publicity

Karen van der Wiel

March 2009 


\title{
Have You Heard the News? How Real-Life Expectations React to Publicity
}

\author{
Karen van der Wiel \\ Netspar, Tilburg University \\ and IZA \\ Discussion Paper No. 4064 \\ March 2009 \\ IZA \\ P.O. Box 7240 \\ 53072 Bonn \\ Germany \\ Phone: +49-228-3894-0 \\ Fax: +49-228-3894-180 \\ E-mail: iza@iza.org
}

\begin{abstract}
Any opinions expressed here are those of the author(s) and not those of IZA. Research published in this series may include views on policy, but the institute itself takes no institutional policy positions.

The Institute for the Study of Labor (IZA) in Bonn is a local and virtual international research center and a place of communication between science, politics and business. IZA is an independent nonprofit organization supported by Deutsche Post Foundation. The center is associated with the University of Bonn and offers a stimulating research environment through its international network, workshops and conferences, data service, project support, research visits and doctoral program. IZA engages in (i) original and internationally competitive research in all fields of labor economics, (ii) development of policy concepts, and (iii) dissemination of research results and concepts to the interested public.
\end{abstract}

IZA Discussion Papers often represent preliminary work and are circulated to encourage discussion. Citation of such a paper should account for its provisional character. A revised version may be available directly from the author. 


\section{ABSTRACT}

\section{Have You Heard the News? How Real-Life Expectations React to Publicity ${ }^{*}$}

As evidence is accumulating that subjective expectations influence behavior and that these expectations are sometimes biased, it becomes policy-relevant to know how to influence individuals' expectations. Information in the media is likely to affect how people picture the future. This paper studies the role of public information dissemination, or publicity, in a reallife expectations formation process. For this purpose, an exceptional Dutch dataset on monthly expectations regarding the future eligibility age for old age social security is analyzed. On average, the publicity reaction in eligibility age expectations is small but the differences among subgroups are considerable. I find that higher educated and high income groups hardly adapt their expectations to relevant publicity. On the contrary, those who do not often read a newspaper have a relatively high publicity reaction. A potential explanation for this latter finding is that these groups have low quality initial expectations. If this is true, publicity thus particularly benefits the initially worse informed groups.

JEL Classification: D83, D84, H55

Keywords: expectations, information, media

Corresponding author:

Karen van der Wiel

Tilburg University

PO Box 90153

5000 LE Tilburg

The Netherlands

E-mail: K.M.vdrWiel@uvt.nl

\footnotetext{
* Thanks to Arthur van Soest, Frederic Vermeulen, James Banks, Jan van Ours and Damjan Pfajfar for useful comments and suggestions. The Dutch government institution that pays out social security benefits, the Sociale Verzekeringsbank, generously funded this research through Netspar, the Network for Studies on Pensions, Ageing and Retirement. This paper was partly written during a research visit at University College London.
} 


\section{Introduction}

Economists like to believe that expectations play a role in almost every decision that economic agents make. In our models, retailers for example have beliefs over competitors' future prices while determining their own price and households are assumed to take their unemployment risk into account before signing a mortgage contract. The academic debate on the actual role of expectations in decision-making is still ongoing though. An expanding literature relates subjective expectations, sometimes measured in probabilities, to individual behavior such as saving, criminal activities and smoking. Interesting papers on the relationship between observed expectations and observed actions include Stephens (2004), Lochner (2007) and Viscusi and Hakes (2008). While I have tried to contribute to this literature in an earlier paper (Van der Wiel, 2008) by showing that old age social security expectations are related to pension scheme participation, the current paper takes one step back.

In this paper I study how public information dissemination influences observed expectations for different demographic groups. As more and more evidence is being presented that subjective expectations are important in decision-making, policy-makers would like to know whether expectations can be influenced through information dissemination in the media. This is important when individuals' expectations are overly optimistic or overly pessimistic. Two examples in the literature of systematically biased expectations are the yen/dollar exchange rate expectations that were too low for Japanese exporting companies (Ito, 1990) and the probabilities of obtaining certain diseases that were too high for Dutch women (Carman and Kooreman, 2007). In assessing the importance of the publicity reaction, I am answering the call for more knowledge on the underlying mechanism generating expectations by both Manski (2004) in his influential paper on measuring expectations ${ }^{1}$ and by Bernanke (2007) in his speech for the NBER monetary economics summer workshop ${ }^{2}$.

In this paper I specifically examine the influence of newspaper publicity on the degree to which individuals' social security expectations change over time. Public information dissemination, or publicity, is defined here as the information concerning the entity at interest that is disseminated through various public media outlets. Publicity can thus contain both new information and repetitions of information that was already known. I find that the aggregate publicity reaction of Dutch households in their old age social

\footnotetext{
1 "I see a critical need for basic research on expectations formation. Understanding how persons revise their expectations with receipt of new information often is a prerequisite for credible use of econometric decision models to predict behavior." (Manski, 2004, p.1371)

2 "We must understand better [...] the relationship between policy actions and the formation of inflation expectations." [...] A fuller understanding of the public's learning rules would improve the central bank's capacity [...] to evaluate the implications of its policy decisions and communications strategy."(Bernanke, 2007, p.4)
} 
security expectations is small, but that certain subgroups of the population, such as the middle-aged and those who infrequently read a newspaper, adapt their expectations relatively often in publicity-rich periods.

Unlike the majority of papers in the empirical expectations formation literature (e.g. Gramlich, 1983, Caskey, 1985, Keane and Runkle, 1990, Souleles, 2004 and Lamla and Lein, 2008), I will not base my findings on inflation expectations. Instead I will analyze the influence of publicity on Dutch old age social security expectations, specifically focusing on individuals' expectations regarding the future eligibility age ${ }^{3}$. I am not the first to look at these expectations. As U.S. social security expectations are best documented, the literature mostly focuses on Americans' perception of their old age benefits (e.g. Dominitz, Manski and Heinz, 2003). Subjective social security expectations have been studied mostly in order to understand the impact of social security policy on retirement savings (e.g. Bernheim and Levin, 1989, Dominitz et al., 2002 and Van der Wiel, 2008).

A major advantage of the Dutch eligibility age expectations over the U.S. expectations is that there cannot be valuable private information involved when Dutch individuals consider the future of their old age social security system. Future benefits perceptions in the U.S. are influenced by individual health, job security and income expectations, besides future policy expectations. The same holds for inflation expectations: private information plays an important role as absorbed price information is so different across consumers. Unlike the U.S. system, Dutch old age social security is uniform and universal, and expectations regarding its future will therefore only reflect general policy expectations. The information set that individuals could use in forming expectations would for example include the debates and decisions of the Dutch Parliament as well as Statistics Netherlands' estimates of future population growth. This information is all publicly known. A lack of relevant private information is necessary in order to distinguish the publicity reactions of different demographic groups. If unobservable private information would also play a role in the eligibility age expectations, I could never separate differences in information absorption from differences in the available information set.

Like in most of the expectations formation literature based on survey data (e.g. Carroll, 2003, Mankiw, Reis and Wolfers, 2003, Souleles, 2004, and Branch, 2004), I also observe a high degree of heterogeneity in the level of expectations. The theoretical model that is the basis for my empirical analysis takes this heterogeneity explicitly into account. I then propose a novel method of assessing the influence of publicity on expectations. This will be done by estimating the proportion of the variance in expectation

\footnotetext{
${ }^{3}$ The Dutch old age social security system, 'AOW', is a universal Pay-As-You-Go pension scheme that is currently rewarded to all Dutch citizens from the age of 65 onwards. The monthly amount an individual receives is independent of contributions, income or wealth.
} 
changes that can be attributed to a publicity reaction. The variance is the relevant unit of analysis here as I am interested in all publicity reactions; i.e. in both positive and negative expectations shifts. The estimator is named the Publicity Reaction Coefficient (PRC) and is estimated for different demographic and media consumption groups. To produce the PRC I use two Dutch datasets: the Pensionbarometer, a monthly Dutch longitudinal household survey of pension policy expectations, and a dataset containing the weekly frequency of newspaper articles on old age social security taken from the LexisNexis database. Naturally, I do not know how many and what newspaper articles individuals read or take notice of when determining expectations. However, I do observe multiple survey periods before which hardly any relevant newspaper articles appeared. The observed expectation changes in these surveys are likely to be realizations of the heterogeneous reporting error term which allows me to estimate the value of the reporting error variance per subsample. The Publicity Reaction Coefficient is then estimated by subtracting this error variance from the variance of expectation changes in high-publicity periods.

It turns out that media coverage of the old age social security system typically accounts for between zero and thirty percent of the variance in expectation changes. Rather than publicity, random shifts thus explain the majority of the variance in changes in eligibility age expectations, with especially older individuals being more imprecise in their expectation reports. When comparing subgroups, I find that middle-aged, those who infrequently read a newspaper, those who consider themselves below-average informed about Dutch politics and those who read free or populist newspapers have a relatively high PRC. These respondents thus change their expectations more after heavy media attention than other demographic groups. On the contrary the old, those with a university degree and those who earn a relatively high income have a low Publicity Reaction Coefficient. These socio-economic groups are thus relatively insensitive to heavy media attention on old age social security. This could be counter-intuitive at first, but several plausible explanations can be identified. First, it becomes understandable when the majority of newspaper articles about the old age social security system contains 'old news'. It is after all likely that those with lower quality initial expectations adapt their expectations more whenever already available information is repeated in the media. The quality of the priors of those with a university degree is probably better so that these respondents can ignore all the information in the media that they were already aware of. If this is the mechanism at play, policy-makers could thus improve the quality of expectations by often repeating already available information in the media. Second, another explanation could be that those for whom the future of old age social security is more important pay more attention to the relevant media exposure. As the old age social security benefit is universal in level, it plays a minor role in the pension income of high income individuals. Hence, the 
high-income group probably does not read the relevant newspaper articles as interestedly as middle-income individuals. The same holds for those over the age of 64 as changes in the social security eligibility age will probably not affect them anymore. If this is the mechanism at play, policy-makers could probably not improve the quality of expectations by often repeating already available information in the media, as those who want to know already pay attention to the available publicity. Additional research is needed to find out more about the mechanisms that drive the differences in publicity reaction between demographic groups.

This paper will proceed with an overview of some of the relevant economic literature in Section 2. I then propose an econometric approach to estimate the Publicity Reaction Coefficient in Section 3. Furthermore, I describe the Pensionbarometer dataset (Section 4) and the information set that was available to respondents during the observation window (Section 5). Section 6 presents the results of the empirical analysis. Section 7 concludes.

\section{Literature}

In this section I will present some of the relevant economic literature on expectations formation and the role that publicity could play in this process. As the contribution of this paper is the empirical analysis of a unique expectations dataset I am however not exhaustive here. Interesting parallels with the subjective health expectations literature and asset pricing literature could be drawn, but were omitted in order to be as concise as possible.

Before data on subjective expectations were available, economists already formulated models for expectations formation in order to complete their theoretical and structural models. Especially in monetary economics it is of the utmost importance how expectations formation is modeled. Most of these expectations formation theories have one thing in common; they link the relevant information that is available at time $t$ to what organizations, firms and individuals expect to happen at time $t+1$. Among the first to formalize a theory on expectations formation were Arrow and Nerlove (1958) who expanded the adaptive expectations theory in which one learns from previous prediction errors. Another well-known example of such a theory is the rational expectations hypothesis proposed by Muth (1961). He introduced the convenient notion that individuals and firms use all the currently available information in a correct way so that they compute perfect, or unbiased, expectations. Given the evidence of judgement biases in simple evaluation tasks (e.g. Tversky and Kahneman, 1974), the rational expectations assumption is unlikely to hold in reality. Several authors have indeed shown that not all relevant and available information is incorporated in expectations (e.g. Figlewski and Wachtel, 1981, and Carroll, 2003) and that changes in expectations are typically more extreme than ex-post justified (e.g. De Bondt and Thaler (1990)). Given that most of these studies ana- 
lyze inflation or exchange rate expectations of professional forecasters, the extent to which expectations of the general public are biased is probably even larger.

Out of discontent with the standard rational expectations assumption, Mankiw and Reis (2002) introduced a more realistic theory: the sticky expectations model. In this expectations formation model all new information is correctly absorbed in the expectations of a certain fraction of the population, while another - ignorant - fraction sticks to their previous expectations. Although a vast improvement to the earlier literature on expectations formation, the sticky expectations literature does not discuss which individuals belong to the updating and which belong to the ignorant group. In fact, the theory assumes that each period all individuals are equally likely to update their expectations. It seems more reasonable though that certain individuals are always on top of the news and hence display a strong information reaction, while others systematically ignore the news and hence have more stable expectations.

Some authors have tested the sticky-expectations model by quantifying the fraction of the population that belongs to the ignorant group, typically analyzing ex-post prediction errors in inflation expectations. Mankiw, Reis and Wolfers (2003) estimate that professional economists in the Livingstone survey update their expectations once every ten months and that households in the Michigan Survey update their inflation expectations once every thirteen months. This comes down to more than ninety percent of individuals ignoring new information revelations each month. Carroll (2003) finds that the typical household in the Michigan Survey updates inflation expectations roughly once a year, while unemployment expectations appear to be updated more frequently.

Carroll also pays attention to media intensity on the relevant random variable. He uses the Michigan Survey to find that inflation expectations are more accurate in periods before which there is a lot of news coverage on inflation and also that the updating speed in the total population is faster when there has been more news coverage. In his paper, Carroll provides a micro-foundation for Mankiw and Reis's sticky expectations, as he proposes that the media are the information channel through which individuals, in different degrees, absorb professional forecasters' inflation expectations. Another example of a study in which publicity plays a direct role is a paper by Lamla and Lein (2008) who examined the role of the media in German consumers' inflation expectations. Their findings support Carolls results that more news indeed leads to more expectations updating. Lamla and Lein also investigate the effect of the wording of inflation news and find that the expectation bias increased in periods in which the media were blaming the introduction of the euro for significant price increases. Although they do show that media intensity affects the quality of expectations, neither Carroll nor Lamla and Lein address if and how demographic groups differ in 
their uptake of relevant information in the media.

While ignoring the publicity element of expectations formation, other authors have examined demographic differences in expectations. Several papers have analyzed the differences in ex-post expectation errors between professional forecasters, or economists, on the one hand and households on the other hand (e.g. Gramlich, 1983). Unexpectedly, this comparison does not always favor the professionals. Gramlich also provides sketchy evidence that low-income and low-education households forecast inflation better. He argues that this counterintuitive finding has its origin in the accelerating inflation during the survey period 1978-1979. Congenital pessimists, which he believes low-income and low-educated individuals are, would have had a forecast advantage in that period. Jonung (1981) was one of the first to decompose household inflation perceptions and expectations demographically and he found that women perceived higher inflation rates than men using Swedish data. Jonung suggests that this might have to do with the different products that men and women buy, as especially food inflation had been relatively high in the survey period. This importance of private information sets in inflation expectations has been a major argument to analyze policy change expectations in this paper. Souleles (2004) related macro-economic forecast errors to demographic characteristics and he found that the forecast bias decreased in magnitude with age, income and education. He however does not provide an explanation for this phenomenon.

The sticky-expectations model is thus a promising recent development in the theoretical expectations formation literature that is more realistic than its predecessors. So far, empirical tests of the model suggests that many individuals indeed choose to ignore publicly available information. It now seems policy relevant to shed more light on the heterogeneity in the stickiness of expectations. In this paper I focus on how the updating of expectations differs over various demographic and media consumption groups. This empirical exercise can only be done using an expectation for which private information is unimportant, as this will circumvent many identification issues. In Section $4 \mathrm{I}$ will explain that the expectations regarding the future of the Dutch old age social security eligibility age are perfect for this purpose.

\section{Expectations formation model}

\subsection{A theoretical model of the information reaction}

I consider the following expectations formation model that makes only weak assumptions on the relationship between information, publicity and expectations. Individual $i$ reports expectations at time $t$ over the realization of a random variable $y$ at a specified moment in the future, $t+z$. This expectation will be denoted as $\tilde{y}_{i t}^{t+z}$ and is the sum of three components: a 
function $f_{i}$ of the absorbed information set that is available at time $t, \Omega_{i t}$, a time-invariant component, $v_{i}$, and a reporting error term, $\epsilon_{i t}$. The following equation presents this expectations formation model:

$$
\tilde{y}_{i t}^{t+z}=f_{i}\left(\Omega_{i t}\right)+v_{i}+\epsilon_{i t} .
$$

Individual heterogeneity enters the expectations formation formula in many ways. First, individuals do not necessarily absorb all available information. This means that the personal information set $\Omega_{i t}$ is a subset of the generally available information set $\Omega_{t}\left(\Omega_{i t} \subseteq \Omega_{t}\right)$. Note that this means that private information is excluded in this expectations formation model; individuals differ in their information absorption but they could in principle all access the same knowledge.

A second source of individual heterogeneity resides in how the absorbed information is translated into an expectation. The information processing function $f_{i}(\cdot)$ in the expectations formation model therefore has subscript $i$. Information absorption and information processing are theoretically different concepts - think about the proverb 'In one ear... Out the other'. Unfortunately, it is empirically very difficult to distinguish the two effects. Therefore, I will from now on refer to their combined effect on expectations as the information consumption effect.

The expectations formation model includes two additional sources of interpersonal variation. The constant component $v_{i}$ represents individuals' inherent inclination towards low or high expectations, i.e. towards pessimism or optimism. Moreover, I make assumptions on the distribution of the error term $\epsilon_{i t}$ that allow for individual heteroskedasticity. All assumptions on the error term can be summarized as follows:

$$
\epsilon_{i t} \sim \operatorname{n.i.d.}\left(0, \sigma_{i}^{2}\right) .
$$

The larger the variance of the error term, $\sigma_{i}^{2}$, the larger is the typical deviation in the expectations report from the information-based expectation. In this model, individuals thus differ in the size of these deviations. A way of thinking about this is that someone with a small error variance is a precise individual and someone with a high error variance is a sloppy individual.

One source of heterogeneity in the expectations, namely the individualspecific constant term $v_{i}$, can easily be eliminated by taking first differences. It is important to note that in empirical applications this individual constant term will, besides optimism, also include the influence of initial information on expectations. This is because the expectations formation process will have started (long) before the expectations are first observed by the researcher. The first difference expectations formation model can be found 
below:

$$
\begin{aligned}
\tilde{y}_{i t}^{t+z}-\tilde{y}_{i, t-1}^{t+z} & =f_{i}\left(\Omega_{i t}\right)-f_{i}\left(\Omega_{i, t-1}\right)+\epsilon_{i t}-\epsilon_{i, t-1} \Rightarrow \\
\Delta_{i t} \tilde{y}^{t+z} & =\Delta_{i t} f_{i}(\Omega)+\Delta_{i t} \epsilon .
\end{aligned}
$$

Expectation changes are thus a linear combination of the change in the processed information set that an individual absorbs into her expectations $\left(\Delta_{i t} f_{i}(\Omega)\right)$ and a new error component $\left(\Delta_{i t} \epsilon\right)$. The new errors are by assumption independent normal with mean zero and a variance that is twice the individual error variance $\sigma_{i}^{2}$.

The systematic effect of information on expectation changes $\left(\Delta_{i t} f_{i}(\Omega)\right)$ is what I call the information reaction. In this paper, I am interested in the size of this effect and especially in how this size varies over individuals.

\subsection{Information, publicity and newspaper articles}

Now that it is clear that expectation changes depend on the new information that someone consumes in between two time periods, it is necessary to think about how a person acquires her new expectation formation input. Public information dissemination, or publicity, is likely to play an important part in this information acquisition.

The publicity set, $\Theta_{t}$, is defined here as the set of all information on the realization of the random variable $y$ at time $t+z$ that is disseminated through publicly available media outlets between period $t-1$ and period $t$. These outlets would include television programmes, internet blogs and magazine and newspaper articles. The publicity set, $\Theta_{t}$, can be divided in two separate subsets: the set of truly new information revelations that were unavailable last period, $\Delta_{t} \Omega$, and the set of repeated information elements that were already known last period, $\Phi_{t}$. The exact explanation of the publicity set is given in the following equations:

$$
\begin{aligned}
\Theta_{t} & =\Delta_{t} \Omega \cup \Phi_{t} \\
\Delta_{t} \Omega \cap \Phi_{t} & =\emptyset \\
\Delta_{t} \Omega & \nsubseteq \Omega_{t-1} \\
\Phi_{t} & \subseteq \Omega_{t-1} .
\end{aligned}
$$

Note that the publicity set is defined such that each informational element can only enter the set once, so that the number of times that a certain piece of information is mentioned in the media does not play a role in $\Theta_{t}$.

I will assume that the only sources from which individuals derive new information, $\Delta_{i t} \Omega$, are the public media outlets. I thus exclude library visits and say, university lectures. Note that one does not have to watch a certain television programme oneself to know what it was about. I am allowing for hearing about news from others - colleagues, family, friends - as long as there 
is only a short period between the appearance of the television programme and the informal information dissemination. I furthermore do not allow for lagged publicity effects in my expectation change model. A person that chooses not to read the newspaper in a certain period cannot decide to read it three months later. This is not such a strong assumption as repetitions of existent information $\left(\Phi_{t}\right)$ are an important component of the publicity set $\left(\Theta_{t}\right)$. These two assumptions on the newly absorbed information are summarized as follows:

$$
\Delta_{i t} \Omega \subseteq \Theta_{t} .
$$

Unfortunately, there are two empirical problems concerning the publicity set $\Theta_{t}$. First, as I am interested in quantifying the information reaction in expectations, a quantitative measure of information dissemination is much more useful than a set of informational elements. This is because each element of the information set will have a distinct influence on expectations and these effects cannot be separated empirically. Second, it is technically impossible to exactly observe all informational elements of the publicity set $\Theta_{t}$. Even if a researcher would have time to carefully read the thousands of relevant newspaper articles, there is no way to assemble all television programmes that have featured information on the random variable $y$. Because of these data problems, I will introduce a new quantitative and observable measure of publicity intensity, $\theta_{t}$, which I define as the number of newspaper articles that mention the relevant random variable $y$ in their content (in this paper, the old age social security eligibility age). Newspapers are naturally not the only available media outlet. However, I choose to restrict $\theta_{t}$ to newspaper articles as this is the only information source that can easily be retrieved. The underlying assumption is that the correlation between the publicity intensity across all media outlets is very strong.

A positive relationship between the number of elements in the publicity set $\Theta_{t}$ and the quantitative measure of publicity intensity $\theta_{t}$ is easy to imagine. It is likely that the more newspaper articles appear about a certain subject, the more information about that topic will be disseminated. How strong this relationship is from period to period is hard to say however. One frontpage article by a well-known journalist could have much more influence than a standard press release that has been copied in all large newspapers. I therefore choose not to further formalize the relationship between the content and quantity of media coverage. The only assumption that I am willing to make is that the publicity set $\Theta_{t}$ is empty when the amount of newspaper articles on the relevant variable $y$ is very low, i.e. when $\theta_{t} \approx 0$. What I mean with very low will become explicit in Section 5 of this paper.

It turns out that the restrictions on no lagged publicity and on the relationship between $\Theta_{t}$ and $\theta_{t}$ are very useful assumptions. Together they imply that the information-related component of expectation changes - i.e. the information reaction - will equal zero when the media intensity on the 
random variable is very low. The information reaction in such circumstances is laid out in the equation below:

$$
\Delta_{i t} f_{i}(\Omega)=0 \text { if } \Theta_{t}=\emptyset \text {, i.e. when } \theta_{t} \approx 0 .
$$

Because this proposition requires important assumptions on how individuals obtain their personal information set from the media, it is appropriate to name the information related component of expectation changes the publicity reaction here rather than the information reaction. Although the two are the same by assumption I believe that readers could misunderstand the information effect as having to do with real information revelations only $\left(\Delta_{t} \Omega\right)$ rather than also with repeated elements of the information set $\left(\Phi_{t}\right)$.

Note that a lack of publicity is not the only circumstance as a result of which a zero publicity reaction is observed. The publicity reaction could also be zero when 1) the individual does not absorb any new publicity, 2) all elements of the consumed publicity set were already known to the individual or 3) the individual does not change her expectation after processing the newly absorbed information.

\subsection{Identification of the publicity reaction}

The proposition that the informed component of an expectation does not change whenever the publicity on the realization of the relevant variable has been negligible will prove useful in identifying the actual publicity reaction later on. To see this, let me first define two types of time periods: the set $L$ contains periods in which there is hardly any publicity between $t-1$ and $t\left(t \in L\right.$ if $\left.\theta_{t} \approx 0\right)$ and the set $H$ contains periods before which some publicity, containing real and/or repeated news, is published $\left(t \in H\right.$ if $\theta_{t} \gg$ $0)$. For these period subsets, a different expectation change expression can be written down.

$$
\Delta_{i t} \tilde{y}^{t+z}=\left\{\begin{array}{l}
\Delta_{i t} \epsilon \text { if } t \in L \\
\Delta_{i t} f_{i}(\Omega)+\Delta_{i t} \epsilon \text { if } t \in H .
\end{array}\right.
$$

It turns out that in low-publicity periods expectation changes are only a realization of the change error, while in high-publicity periods the publicity reaction enters the expression as well. In order for this distinction between $L$ and $H$ to be empirically relevant I need to observe expectation changes in time periods in which the quantity of relevant newspaper articles is low $\left(\theta_{t} \approx 0\right)$ and in periods in which it is high $\left(\theta_{t} \gg 0\right)$. I will explain in Section 5 that I indeed observe such periods for my social security policy expectations.

I cannot derive interesting empirical results from the expectations change model in terms of the level of changes. This is because both increases and decreases in expectations could be due to publicity reactions but such observations would cancel out in estimations. Instead, I am interested in the 
variance of expectation changes which, under assumptions, can give me insight into the degree to which expectations are formed by publicity consumption. The traditional variance measure is the second central moment, i.e. the extent to which different observations of a variable typically vary from its mean $\left(E\left[\left(\tilde{y}_{i t}^{t+z}-\overline{\tilde{y}}\right)^{2}\right]\right)$. For the publicity reaction analysis I am however interested in the second moment $\left(E\left[\left(\tilde{y}_{i t}^{t+z}\right)^{2}\right]\right)$ rather than in the second central moment as changes in expectations and not levels are the unit of analysis. Think about an individual that increased her expectation by the same (large) amount for a couple of time periods in a row. The second central moment of this person's expectation changes would equal zero, although it is very well possible that the individual did (strongly) react to publicity. The second moment of her expectation changes will have been relatively large however. In this paper, the word variance will thus represent the second moment of expectation changes, i.e. the average squared expectation changes. This is a very intuitive unit of analysis, as it will always increase in the degree of publicity reaction.

The data at hand does have to satisfy one non-testable assumption in order for the variance to be a suitable unit of analysis. I have to assume that there is no linear relationship between the publicity reaction and the new error term i.e. the covariance between these elements of expectation changes should equal zero:

$$
E\left[\Delta_{i t} f_{i}(\Omega) * \Delta_{i t} \epsilon\right]=\operatorname{Cov}\left(\Delta_{i t} f_{i}(\Omega), \Delta_{i t} \epsilon\right)=0 .
$$

The zero correlation assumption is necessary for the variance of the expectation changes to be the sum of the variance of its components. Note that this relatively weak assumption does not rule out heteroscedasticity. It remains possible for the variance of the change errors $\left(2 \sigma_{i}^{2}\right)$ to be a function of individual time-invariant characteristics. If the covariance is indeed zero, the variance of the expectation changes can be decomposed as in the following equation:

$$
\operatorname{Var}\left(\Delta_{i t} \tilde{y}^{t+z}\right)=\left\{\begin{array}{l}
\operatorname{Var}\left(\Delta_{i t} \epsilon\right)=E\left[\left(\Delta_{i t} \epsilon\right)^{2}\right] \text { if } t \in L \\
\operatorname{Var}\left(\Delta_{i t} f_{i}(\Omega)+\Delta_{i t} \epsilon\right) \\
=E\left[\left(\left(\Delta_{i t} f_{i}(\Omega)\right)^{2}\right]+E\left[\left(\Delta_{i t} \epsilon\right)^{2}\right] \text { if } t \in H .\right.
\end{array}\right.
$$

The periods with very little publicity on the variable that individuals have expectations over $(L)$ can now be exploited to identify the proportion of the variance in expectation changes related to publicity. A two-step procedure has to be applied. First, I can estimate the variance of the error component in expectation changes by computing the average squared expectation change in the low-publicity periods. Second, I can decompose the total variance in publicity-rich periods $(H)$ into the variance of the publicity reaction and the variance of the error term which is estimated in the 
first step. This can be done as I assume that the variance of the reporting error term is constant over time, so that the variance of the error term in low-publicity times will be similar to that in high-publicity times. This procedure then generates an estimate of the proportion of the variance in expectation changes that is related to information dissemination:

$$
\begin{aligned}
\widehat{\operatorname{Var}\left(\Delta_{i t} \epsilon\right)} & =E\left[\left(\Delta_{i, t^{L}} \tilde{y}^{t+z}\right)^{2}\right] \\
\left.\operatorname{Var} \widehat{\left(\Delta_{i t} f_{i}\right.}(\Omega)\right) & \left.=\operatorname{Var}\left(\Delta_{i, t^{H}} \tilde{y}^{t+z}\right)-\operatorname{Var(\Delta _{it}} \epsilon\right) \Rightarrow \\
& =E\left[\left(\Delta_{i, t^{H}} \tilde{y}^{t+z}\right)^{2}\right]-E\left[\left(\Delta_{i, t^{L}} \tilde{y}^{t+z}\right)^{2}\right] .
\end{aligned}
$$

When an estimate of the variance of the publicity reaction exists, I can say something on the importance of publicity in the expectations formation process relative to the importance of noise. I can calculate the Publicity Reaction Coefficient (PRC), which is defined as the ratio of the estimated systematic variance over the total variance of expectation changes. The higher the PRC, the more important is the role of information dissemination in expectation changes. Equation 1 displays how the Publicity Reaction Coefficient is constructed.

$$
P R C=\frac{\left.\operatorname{Var} \widehat{\left(\Delta_{i t} f_{i}\right.}(\Omega)\right)}{\operatorname{Var}\left(\Delta_{i t} \tilde{y}^{t+z}\right)}=\frac{E\left[\left(\Delta_{i, t^{H}} \tilde{y}^{t+z}\right)^{2}\right]-E\left[\left(\Delta_{i, t^{L}} \tilde{y}^{t+z}\right)^{2}\right]}{E\left[\left(\Delta_{i, t^{H}} \tilde{y}^{t+z}\right)^{2}\right]}
$$

The Publicity Reaction Coefficient is ideally estimated on the individual level. This can be done when sufficient observations are available on the individual level in both publicity-poor and publicity-rich periods. Especially the number of low-publicity observations is important because these are used to estimate the variance of the new error term which should be consistently estimated. One can imagine that at least 30 expectations observations in low-publicity periods would be necessary to do so. Unfortunately the dataset that I will be using is not long enough to meet this criterium. Therefore the reporting error variance and consequently the PRC will be estimated for different demographic and media consumption subgroups rather than per individual. The subscript $i$ in this section should for my empirical application thus be interpreted as representing different groups rather than persons. The estimated group-PRC's will still be very relevant as these will allow me to draw conclusions on how the publicity reaction in expectations differs across relevant groups in the population. It seems policy relevant to know whose expectations (over)react to publicity and who displays large reporting errors. If such groups could be identified, information campaigns could for example be better targeted.

\subsection{The prediction error variance estimated}

Under the assumption of normality of the reporting error term it is furthermore possible to see how the noise variance $\sigma_{i}^{2}$ is related to demographics. 
Although this is not central to the publicity reaction analysis, it is nevertheless interesting to see which groups are more prone to errors in their expectation estimates. I choose to model the heteroscedasticity in the variance of $\Delta_{i t} \epsilon$ in the multiplicative fashion that is often used. Like in the textbook examples, I thus work with the assumption that the individual variance equals an exponential function. The squared expectation changes in periods before which no publicity entered the scene $(t \in L)$ can then be seen as drawings from the variance distribution. If I moreover take logs on both sides, the model simplifies to a linear equation which can be estimated using OLS. These steps are laid out in the equations below. The $\gamma$-coefficients will tell me who is more precise and who is more sloppy by nature:

$$
\begin{aligned}
\widehat{\operatorname{Var}\left(\Delta_{i t} \epsilon\right)} & =E\left[\left(\Delta_{i, t^{L}} \tilde{y}^{t+z}\right)^{2}\right] \\
\left(\Delta_{i, t^{L}} \tilde{y}^{t+z}\right)^{2} & =2 * \sigma_{i}^{2}=2 * e^{\left(\alpha+x_{i}^{\prime} \gamma+\eta_{i t}\right)} \\
\ln \left(\left(\Delta_{i, t^{L}} \tilde{y}^{t+z}\right)^{2}\right) & =(\ln (2)+\alpha)+x_{i}^{\prime} \gamma+\eta_{i t} \\
\eta_{i t} & \sim \text { n.i.d. }\left(0, \varsigma^{2}\right) .
\end{aligned}
$$

\section{Expectations data}

\subsection{The Pensionbarometer}

Although this paper wishes to say something about the publicity reaction in general, the expectations that will be empirically examined are people's beliefs over the future of the Dutch old age social security eligibility age. This subjective expectation is interesting and useful in the publicity reaction analysis for the following four reasons. First, as the Dutch old age social security system (the 'AOW') is completely universal, i.e. all individuals receive a similar level of benefits from the same age onwards irrespective of contributions paid, all forecasts about potential policy changes refer to the same random variable. The expectations are therefore fully comparable. Second, the majority of individuals expects to grow old and therefore to receive the non-negligible 'AOW' benefits at some point in time. Hence, the future of the old age social security system is of direct consequence to respondents, thereby enhancing the quality of answers provided. Third, as the future of the old age social security system basically depends on a few individuals only (i.e. on 150 members of parliament) and as the debate about its sustainability is followed closely by the media, I claim that all the information that could enter the formation process of eligibility age expectations is publicly available. This implies that differences in expectations

\footnotetext{
${ }^{4}$ In 2008 the 'AOW' benefit was equal to gross $€ 997,12$ for a single individual and $€ 682,51$ for a cohabitating individual. Note that gross would almost have been equal to net in this case.
} 
only reflect differences in which pieces of information individuals absorb and on how this information is processed, not on which information individuals actually have access to.

The expectations data analyzed in this paper is taken from a Dutch survey on pensions' opinions and expectations, the Pensionbarometer, which is collected by CentERdata at Tilburg University in the Netherlands. Netspar, a Dutch research network on pensions, ageing and retirement, has funded the data collection process. The Pensionbarometer is collected mainly to produce longitudinal statistics for confidence-levels in the Dutch pension system. Every month about 500 individuals are asked to answer a few general questions about social security, pensions and retirement via the internet. The respondents are randomly selected from the CentERdata internetpanel, which in turn is a random sample of the population drawn from the municipal registry. Whenever a selected individual does not have access to the internet, CentERdata makes sure that access is arranged. The Pensionbarometer is designed as a panel-type survey, and every respondent receives the questionnaire every three months so that there are in total three recurring groups of respondents. This was done to be able to produce the confidence statistics monthly while not overwhelming the respondents with questions. In this paper, I use the first thirty-one waves of the Pensionbarometer (16,669 observations). The first wave of the survey was enumerated in May, 2006. The last wave that is included in my analysis was enumerated in November, 2008. A total of 2,573 individuals were interviewed. Individuals participated eight times on average. 296 individuals reply only once (there is replacement sampling) and 707 individuals answer the probability questions ten or more times.

The Pensionbarometer asks a series of four questions about individuals' eligibility age expectations that read as follows:

"What is the probability (between 0 and 100) that within ten years/ within twenty years the 'AOW'-eligibility age will be ...

- higher?

- higher by at least two years?

- lower?

- lower by at least two years?"

The questions were always asked in the order above. Four rather then one questions were posed to provide insight in the internal consistency and underlying distribution of the expectations. For longitudinal studies it is however more interesting to examine each question separately as this allows me to focus on changes in expectations. Although the total sample PRCs in the other probabilities will also be reported, I therefore estimate the subgroup Publicity Reaction Coefficients using the first question on a higher eligibility age.

Each Pensionbarometer survey, the time horizon for which an individual 
is asked her expectations is randomly chosen and this time horizon thus varies over the surveys for each individual. The questions either concern a ten or a twenty years time horizon. As I believe there is no clear, cardinal relationship between the ten and twenty year expectations I will report the results for both horizons separately. This leaves me with a first sample of expectation levels with 8,521 ten year observations (2,339 individuals) and 8,148 twenty year observations (2,322 individuals). A second sample of expectation changes is smaller for two reasons. First, the initial Pensionbarometer wave drops out when changes are considered. Second, consecutive expectation answers over different time horizons - when for example first ten year expectations are given and later twenty year expectations - are also ignored. A change in expectations could in such a case namely also reflect a different opinion on the time horizons rather than it being a result of a publicity reaction. I lose 4,646 first wave observations and another 6,716 observations because the time horizon that the individual was asked to provide an expectation over changes from one survey to the next. This leaves me with a second sample of 2,736 ten year expectation changes (1,296 individuals) and 2,571 twenty year expectation changes (1,283 individuals).

The Pensionbarometer also enumerates several important demographic characteristics such as education level, age and income. The Publicity Reaction Coefficient of all relevant subgroups will be estimated in Section 6 . Three independent variables concern media consumption, which will be interesting when analyzing the publicity reaction. The media consumption data is based on additional questions that were asked to all respondents in June 2008. Unfortunately, this means the media information is not available for all respondents, but only for 987 of them. Two questions about direct media consumption read:

"How often do you read a newspaper (free papers and internet papers included)?"

and

"How often do you watch a regular news bulletin on the television?"

The response scales individuals could use were 1) Every day, 2) Multiple times a week, 3) Once a week, 4) At least once a month, 5) Less than once a month. The distribution of answers over these scales can be found in Table 1 . The Pensionbarometer sample is relatively well-read and frequently watches news bulletins on television. More than sixty percent of respondents state that they read the newspaper on a daily basis. It should be noted that newspaper take-up is generally high in The Netherlands. The Dutch Bureau of Statistics reports that in $200651 \%$ of the population had a paid newspaper subscription. For the empirical analysis of this paper I 
Table 1: Frequencies of informative media consumption - in terms of newspaper and television bulletins - for respondents in second sample.

\begin{tabular}{|l|l|l|}
\hline & Newspaper & Television news \\
\hline \hline Every day & $66 \%$ & $61 \%$ \\
\hline Multiple times a week & $18 \%$ & $30 \%$ \\
\hline Once a week & $7 \%$ & $5 \%$ \\
\hline At least once a month & $2 \%$ & $2 \%$ \\
\hline Less than once a month & $6 \%$ & $3 \%$ \\
\hline \hline Observations & 987 & 987 \\
\hline
\end{tabular}

Table 2: Response frequency for which newspaper the respondents most read in second sample.

\begin{tabular}{|l|l|}
\hline & Most read \\
\hline \hline Free newspapers & $12 \%$ \\
\hline 'De Telegraaf' (populist) & $11 \%$ \\
\hline 'De Volkskrant' (progressive) & $10 \%$ \\
\hline 'NRC Handelsblad' (liberal) & $7 \%$ \\
\hline Other & $60 \%$ \\
\hline \hline Observations & 926 \\
\hline
\end{tabular}

have transformed the consumption data in two dummies for relatively low media consumption: low newspaper consumption (once a week or less) and low television news consumption (once a week or less). This was done because the latter categories contain relatively little observations. I performed sensitivity analysis for the results in Section 6 using a different threshold for the dummy which had little effects on the results.

I also know which newspaper the respondents most often read, as they were asked to state from which newspaper they typically obtained most information. The frequencies can be found in table 2 . The most read category are the free newspapers which are distributed in and around public transport and in communal buildings such as Metro, 'Spits' and 'De Pers'. $12 \%$ of respondents indicate that they obtain most information from these sources. Other large categories are two morning quality newspapers, one more conservative/ populist - 'De Telegraaf' and another more progressive - 'De Volkskrant'5. It will be interesting to see whether the slant of a newspaper affects how individuals absorb publicity into their expectations in the empirical section.

Additionally, respondents were asked to rate their own knowledge of

\footnotetext{
${ }^{5}$ The classification of newspapers according to their tone or background is taken from a newspaper article in the 'NRC Next' on the 4th of March 2009.
} 
Table 3: Response frequency for subjective political informedness for respondents in second sample.

\begin{tabular}{|l|l|}
\hline & Being informed \\
\hline \hline Very bad & $3 \%$ \\
\hline Bad & $14 \%$ \\
\hline Average & $52 \%$ \\
\hline Well & $28 \%$ \\
\hline Very well & $4 \%$ \\
\hline \hline Observations & 987 \\
\hline
\end{tabular}

current political events. The exact question posed read:

"Compared to the average Dutch person, how well informed are you about current affairs in Dutch politics?"

Respondents could choose from five answer categories: 1) Very bad, 2) Bad, 3) Average, 4) Well, 5) Very well. Table 3 shows that the Pensionbarometer respondents consider themselves relatively well-informed, although still sixteen percent believe that they know less than the average Dutchmen. In Section 6 I translate this data into a dummy for being relatively ill-informed (very bad and bad answer categories). This partition was chosen as it best explains the differences in empirical publicity reactions.

\subsection{Characteristics of the expectations formation process}

In this section I present some noticeable facts of the expectations formation process that are observed in the data. Whenever statistics on the expectation levels are reported I have used the first sample $(\mathrm{N}=16,669)$, whereas I am using the second sample $(\mathrm{N}=5,307)$ whenever statistics on expectation changes are discussed.

Figure 1 sheds some light on the development of the average subjective expectations over all waves and both time horizons. Each data-point represents the mean of about 250 observations. The observed average probability of later benefits is well above 50 (i.e. a probability of one half) for all waves and both time horizons. Hence, pessimism prevails. The average does vary over the relevant time horizon. As one would expect, people believe that the probability of a policy change within the next twenty years is higher (average is 65) than within the next ten years (average is 61). This difference was consistent in all but one waves. The Pensionbarometer respondents were most optimistic around the end of 2006/ beginning of 2007 (when a new government was being formed) and most pessimistic around the summer of 2008 (when a government appointed committee proposed to raise the eligibility age to 67 years). The average probability seems considerably volatile; the difference between the smallest and largest average 
Figure 1: Average probability assigned to higher eligibility age for both time horizons (week 1-52: 2006, week 53-104: 2007, week 105-157: 2008).

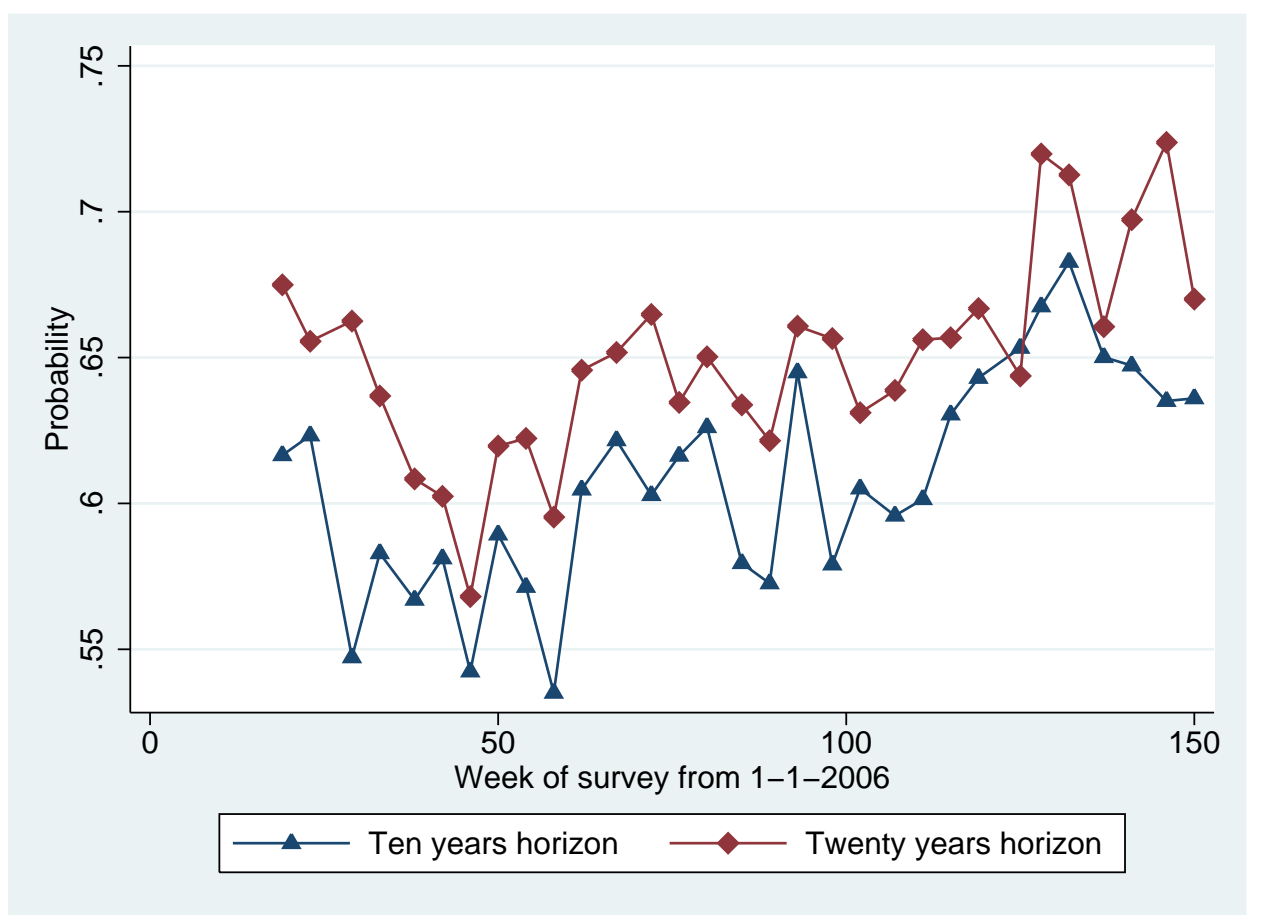

probability is about 15 probability points for both the ten and the twenty year expectations. Note that I choose to name high probabilities pessimistic here and low probabilities optimistic out of convenience; this does not mean to say that I have an objective rationale to label the high or low answers normatively.

A histogram in Figure A-1 in the appendix provides more information on the distribution of the twenty year answers. A clustering of probabilities around 50 is visible. It has been argued that respondents also provide a fifty percent chance response when they have no idea what probability to assign. Manski (2004) however argues that "This concern has largely been laid to rest as empirical evidence has accumulated." (p. 1342). Also given that only one percent of respondents always answer 50 to both the ten and twenty year horizon questions I will assume here that all 50 answers represent true opinions.

Although in general respondents are pessimistic about the future of the old age social security eligibility age, considerable heterogeneity in expectations exists. Figure A-2 in the appendix represents the median and the 25th and 75th percentile for the expectations with a twenty year time horizon. The average interquartile range is substantial and relatively constant over time, at about 40 probability points. 
This individual heterogeneity in the assessment of future policy changes is to a certain degree persistent. Those individuals who assign a higher (or lower) than average probability in one period are more likely to do so in the next period. Using the second sample, I find that the probability of assigning a higher than average probability to a policy change in two consecutive periods is equal to $74 \%$ for the ten year expectations and $67 \%$ for the twenty-year expectations. The probability of assigning a lower than average probability twice in a row is $77 \%$ for the ten year expectations and $77 \%$ for the twenty year expectations. This means that despite the general tendency to remain less or more optimistic than others, still more than twenty percent of individuals move their expectation to the other side of the distribution from one period to the next.

The vast majority of individuals, also those who remain on one side of

Figure 2: Percentage of respondents adapting eligibility age expectations since last survey per week (week 1-52: 2006, week 53-104: 2007, week 105157: 2008).

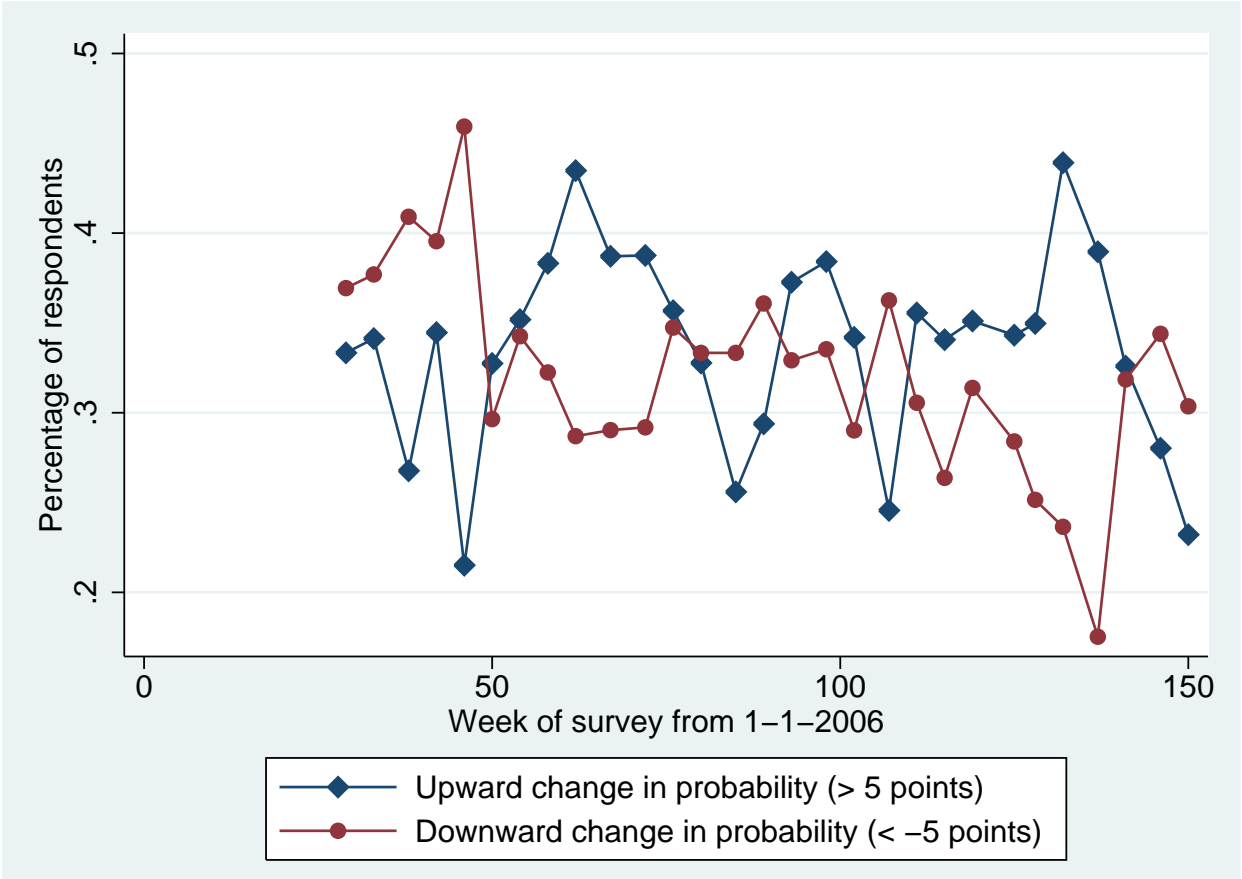

the average expectation, alter their stated expectations between consecutive surveys. Figure 2 shows the percentages of respondents that change their subjective probabilities by more than five points compared to their previous answer. Absolute changes below five probability points are ignored as these could just be due to rounding differences. Remember that my second sample only includes observations of individuals who happened to have 
answered questions for a similar time horizon in two adjacent surveys and that expectation changes are thus measured over a three month period. The average percentage of respondents that display a positive change equals $34 \%$ and the average percentage of respondents that display a negative change over all waves equals $32 \%$. About seventy percent of individuals thus significantly update their beliefs within three months. Moreover, only six percent of respondents never change their expectations by more than five probability points.

Table 4 finally displays the regression results of two-limit Tobit regressions of the subjective probability of a higher eligibility age on some relevant demographic characteristics for both the ten and the twenty year expectations. A tobit estimation technique was chosen to accommodate censoring of the given probabilities at 0 and 100. In both time horizon regressions, the older one gets, the more optimistic one becomes. Also persistent in both columns; respondents with relatively higher incomes as well as those with a partner are significantly more pessimistic. Gender furthermore influences the short-term social security expectations. Women assign higher probabilities to an increase in the eligibility age within ten years. Education moreover has a significant influence on the long-term eligibility age probabilities. Those who completed a higher vocational or an academic education are significantly more pessimistic about the future. Despite the significant covariates, individual heterogeneity and noise seems to be most important in explaining differences in expectation levels as the regressions only explain about $0.4 \%$ of the variation in expectations. 
Table 4: Coefficients and standard errors of two-limit Tobit regressions. Dependent: probability of higher eligibility age between 0 and 100 .

\begin{tabular}{lcccc}
\hline \hline & \multicolumn{2}{c}{10 years } & \multicolumn{2}{c}{ 20 years } \\
& Coef. & S.e. & Coef. & S.e. \\
\hline Vocational secondary & $-4.638^{*}$ & $(1.90)$ & -1.341 & $(2.940)$ \\
General secondary & -1.317 & $(2.11)$ & 3.845 & $(3.124)$ \\
Vocational tertiary & 0.052 & $(2.01)$ & 1.430 & $(3.016)$ \\
Higher vocational & 1.803 & $(1.98)$ & $4.921^{*}$ & $(2.950)$ \\
Academic education & 1.865 & $(2.21)$ & $7.709^{* * *}$ & $(3.158)$ \\
Age 15-24 & -7.106 & $(35.84)$ & -0.163 & $(1.865)$ \\
Age 35-44 & $-6.414^{* * *}$ & $(1.42)$ & $-6.305^{* * *}$ & $(1.631)$ \\
Age 45-54 & $-8.283^{* * *}$ & $(1.36)$ & $-5.281^{* *}$ & $(1.616)$ \\
Age 55-64 & $-11.889^{* * *}$ & $(1.38)$ & $-8.880^{* * *}$ & $(1.721)$ \\
Age >64 & $-14.394^{* * *}$ & $(1.40)$ & $-14.086^{* * *}$ & $(1.761)$ \\
Low middle income & 1.954 & $(1.31)$ & 0.385 & $(1.753)$ \\
Middle income & $5.828^{* * *}$ & $(1.42)$ & $4.968^{* * *}$ & $(1.872)$ \\
High middle income & $5.350^{* * *}$ & $(1.48)$ & $4.895^{* *}$ & $(1.965)$ \\
High income & $6.049^{* * *}$ & $(1.62)$ & $5.824^{* * *}$ & $(2.094)$ \\
Dummy female & $2.570^{* *}$ & $(0.99)$ & 0.316 & $(1.307)$ \\
Dummy partner & $6.318^{* * *}$ & $(0.99)$ & $6.476^{* * *}$ & $(1.296)$ \\
\hline Observations & 8,450 & & 8,087 & \\
Individuals & 2,317 & & 2,290 & \\
Censored at 0 & 288 & & 231 & \\
Censored at 100 & 1,285 & & 1491 & \\
Pseudo $R^{2}$ & $0.40 \%$ & & $0.42 \%$ & \\
\hline \hline
\end{tabular}

Standard errors in parentheses

${ }^{*} p<0.05,{ }^{* *} p<0.01,{ }^{* * *} p<0.001$

Base categories: primary education, age 25-34, low income 


\section{Publicity set}

The publicity set $\Theta_{t}$ is defined in Section 3 as the set of all informational elements on the realization of the relevant entity (here the old age social security eligibility age) that is disseminated through publicly available media outlets between two survey periods. These outlets include for example television programmes, internet blogs and magazine and newspaper articles. As explained before, the publicity set contains both new informational elements, $\Delta_{t} \Omega$, and repetitions of already available information, $\Phi_{t}$. Because it is empirically very difficult to identify the exact elements in and the precise size of the publicity set, Section 3 already introduced the quantity of newspaper articles, $\theta_{t}$, as a reasonable proxy for the intensity of publicity in a given period. Carroll (2003) and Lamla and Lein (2008) also use the number of newspaper articles in their papers. In the theoretical section it is explained that on the relationship between the publicity set and the number of published newspaper articles the only necessary assumption to estimate the Publicity Reaction Coefficient is that no information is disseminated whenever the number of relevant newspaper articles has been very low.

The data on the quantity of newspaper articles is assembled through an online database of written Dutch media content, LexisNexis. Every piece of text that is published in large magazines and newspapers can be retrieved through this database. For each week between the first wave of the Pensionbarometer (week 19 in 2006) and the last reported wave (week 46 in 2008) I have selected all relevant articles that appeared in Dutch national newspapers. Four different series of weekly quantities were generated that could partly overlap: the number of articles containing the acronym 'AOW' in their title, the number of articles containing the acronym 'AOW' in their introduction, the number of articles containing the word 'AOW (eligibility) age' in their total content and the number of articles containing the word 'ageing' in their introduction. Note that 'AOW' is the acronym of the Dutch equivalent of old age social security. Figure 3 displays these four series separately. Considerable variation in the number of relevant newspaper articles can be seen, with especially the middle time period low in media attention for all four series.

Some peaks in the publicity quantities have a real information cause and these events are indicated with vertical lines in Figure 3. Here is a summary of important events related to old age social security during the period May 2006 - November 2008: a) April 2006: The leader of the socialdemocrats (Mr. W. Bos) gives a speech in which he promotes higher tax rates for retired individuals. These rates had been lower because those over 64 do not pay old age social security contributions; b) August 2006: The presentation of general election programs by all relevant parties. Most parties, including the liberals and Christian-democrats, promise to keep the old age social security scheme exactly as it is. Some small parties propose 
Figure 3: Weekly number of news paper articles in Dutch national media featuring words relevant to the old age social security system and special interest weeks (a-f) (week 1-52: 2006, week 53-104: 2007, week 105-157: 2008).
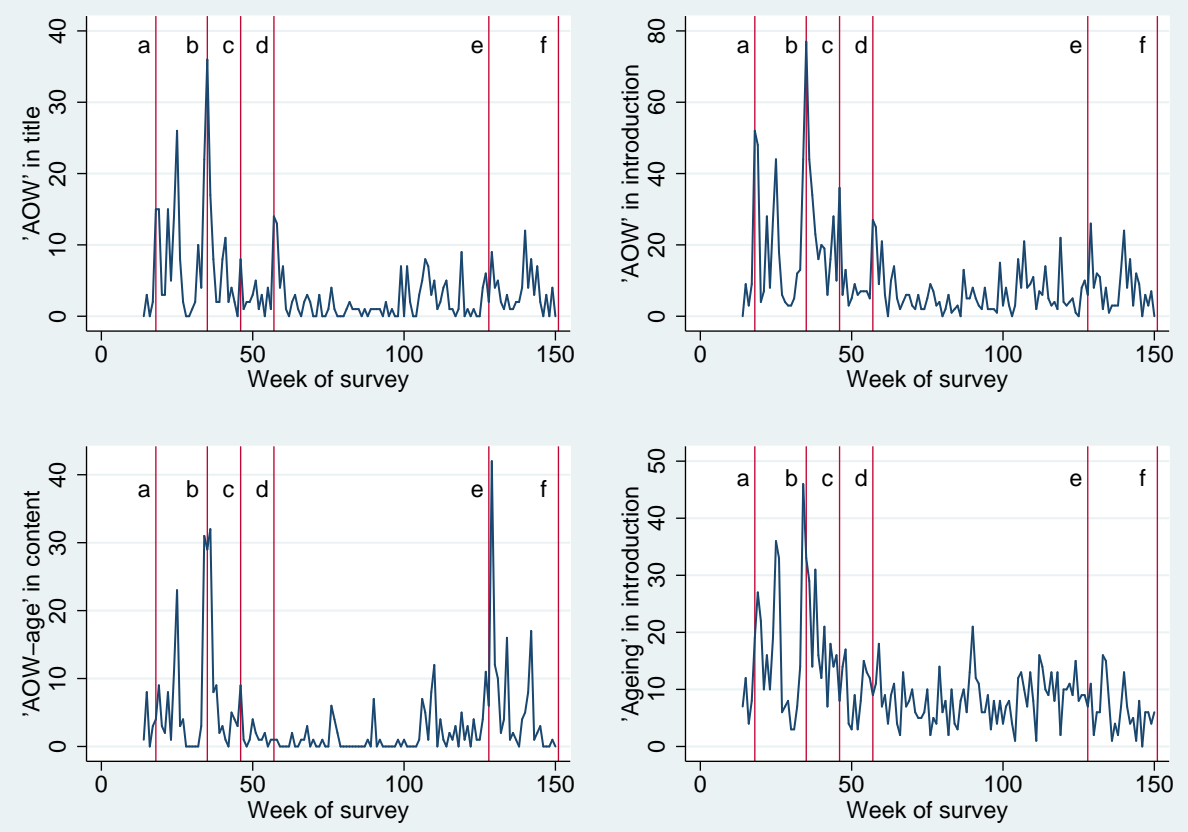

to raise the eligibility age. The social-democrats stick to their idea to alter the contributions scheme; c) November 2006: The election results come in. Relatively to polls half-a-year earlier, the Christian-democrats win and the social-democrats loose, mainly due to the unpopular social security contributions policy proposal; d) February 2007: A coalition government of Christian-democrats and social-democrats is formed and a compromise to increase tax rates for rich retired individuals is revealed; e) June 2008: A special government-appointed committee ('committee Bakker') of prominent social- and Christian-democrats that was asked to think about labor force participation in the long run proposes to e.g. increase the social security eligibility age by two years from 65 to 67 years. The government officially rejects this idea immediately; f) November 2008: Parliament accepts a new taxation law that introduces marginally higher tax-rates for those over 64 and also a tax credit for those between 61 and 65 who are still employed. Note that from this short description of events, it becomes clear that for more than a year, between March 2007 and May 2008, the discussion about the future of Dutch old age social security disappeared from the political scene as other matters were more pressing (such as employment protection). 
This period will be very useful in identifying the variation in expectations that can be attributed to noise.

The quantity of newspaper articles that matters for the publicity reaction in expectations is actually the number of newspaper articles that have appeared since the last time someone participated in the survey, as those will be the potential inputs for changes in expectations. Remember that although the Pensionbarometer is surveyed each month, a single respondent only participates in it every third month. The relevant quantity here is thus the cumulative number of newspaper articles that have been published over these three months since the respondent last answered an expectation question.

Figure 4: Cumulative newspaper articles three months before each survey, relative to median per variable. Low publicity periods between dotted lines (L). Very-high publicity periods between dashed lines (HH).
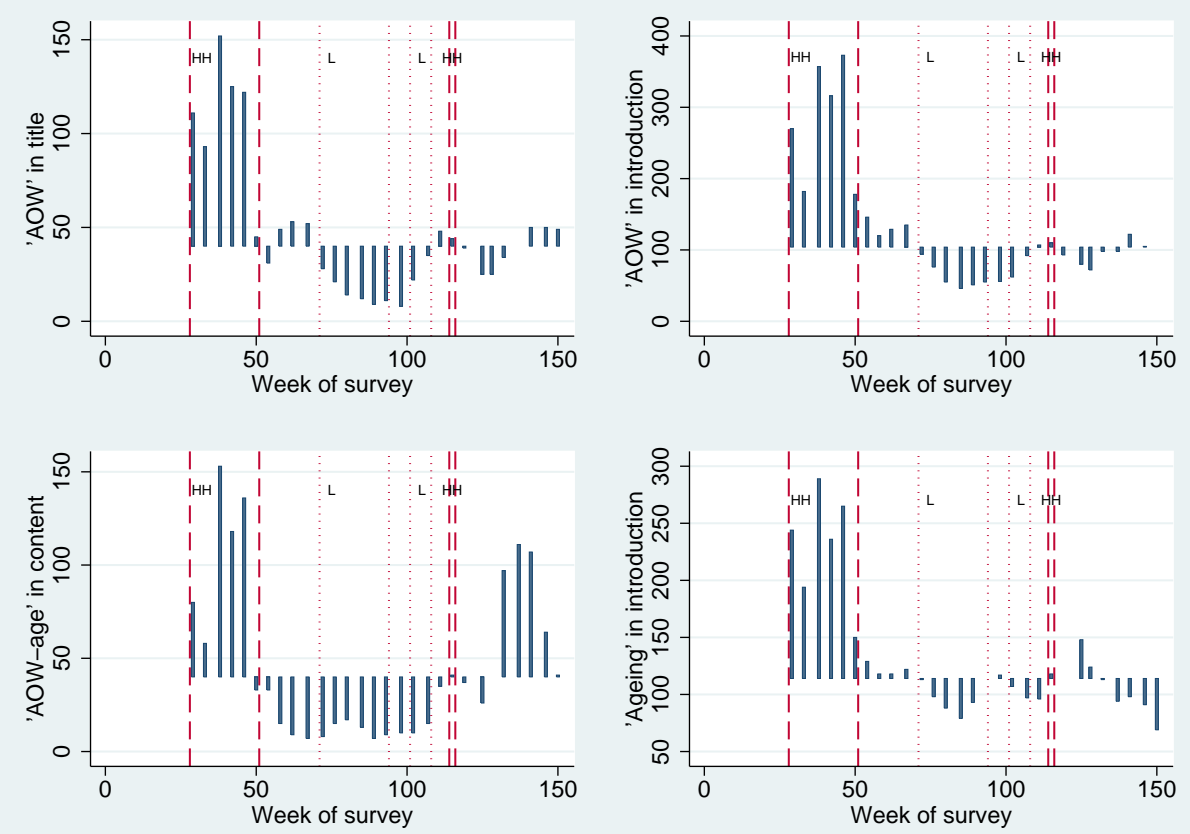

To estimate the Publicity Reaction Coefficient my survey span has to include periods in which hardly any newspaper articles appeared $\left(\theta_{t} \approx 0\right)$. I will now introduce two different definitions of low-publicity periods, based on the four different series in Figure 3. A period is qualified as a standard low-publicity period when the quantity of articles for all four publicity series was below the median of that variable. The bar plots in Figure 4 show these cumulative series per survey week in comparison to their respective medians. The publicity-low periods (L) are those in between the dotted lines. In 
Figure 5: Cumulative news paper articles three months before each survey, relative to first quartile per variable. Very-low publicity periods between dotted lines (LL). High publicity periods between dashed lines $(\mathrm{H})$.
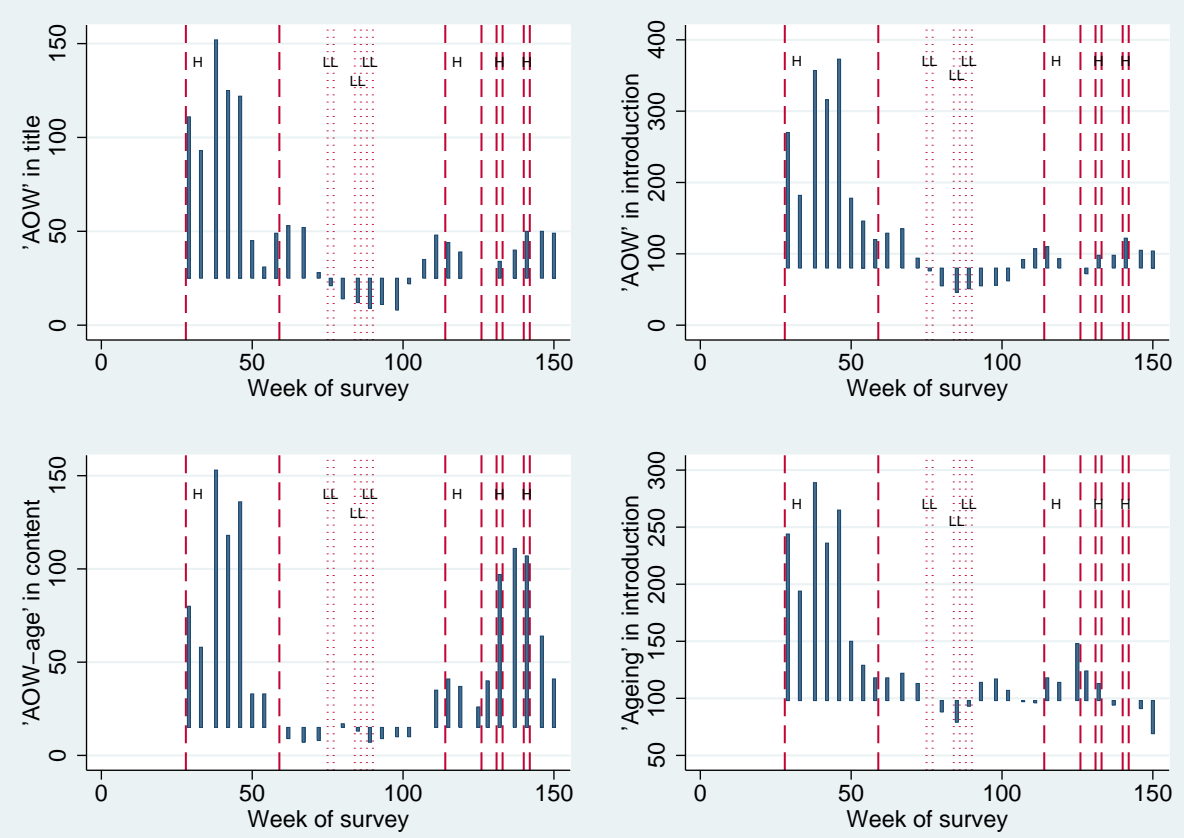

total eight periods can be classified as information-low using this definition. In the same figure, very-high publicity periods ( $\mathrm{HH})$ are identified as those periods before which there was more than the median level of publicity in all four series. The dataset contains seven of these periods. Table A-1 in the appendix provides a list of all periods and their categories.

For the purpose of sensitivity analysis in Section 6 a second definition of publicity-poor periods is introduced, based on the first quartile of the article quantities rather than on the median. Figure 5 shows the cumulative number of articles compared to their respective first quartiles. A period is qualified as a very-low publicity period (LL) when the quantity of articles for all four publicity series was below the first quartile of that variable. The very-low publicity periods are those in between the dotted lines in Figure 5. Only three periods can be classified as information-low using this definition. In the same figure, high publicity periods $(\mathrm{H})$ are identified as those periods before which - for all four series - more newspaper articles appeared than their respective first quartile. There are thirteen of such high-publicity periods. 


\section{Empirical results}

\subsection{Reduced form analysis}

This subsection presents reduced-form results of the extent to which the variance of expectation changes and publicity intensity are related. This is done to investigate whether more publicity before a survey indeed leads to larger changes in expectations. Table 5 presents the results of OLS regressions of the logarithm of squared changes in the higher eligibility age expectations on publicity intensity and several other covariates that control for individuals' propensity to change their expectations. In table 5 each newspaper articles-coefficient was estimated in a separate model, on both the entire sample (column I) or the ten years (column II) and twenty years horizon (column III) subsamples.

The results suggest that higher publicity levels are significantly associ-

Table 5: Selected coefficients and standard errors of separate OLS models. Dependent variable: logarithm of squared expectation changes in higher eligibility age expectations. Newspaper article series in units of 100 .

\begin{tabular}{|l||c||c|c|}
\hline & All & $\begin{array}{c}(\mathrm{II}) \\
\text { Ten years }\end{array}$ & $\begin{array}{c}\text { (III) } \\
\text { Twenty years }\end{array}$ \\
\hline \hline Articles 'AOW' & $0.252^{*}$ & 0.255 & 0.232 \\
in title & $(0.114)$ & $(0.155)$ & $(0.171)$ \\
\hline Articles 'AOW' & $0.115^{*}$ & 0.124 & 0.099 \\
in introduction & $(0.048)$ & $(0.067)$ & $(0.073)$ \\
\hline Articles 'AOW-age' & 0.006 & -0.054 & 0.064 \\
in total content & $(0.093)$ & $(0.129)$ & $(0.141)$ \\
\hline Articles 'Ageing' & $0.231^{* *}$ & $0.227^{*}$ & 0.226 \\
in introduction & $(0.076)$ & $(0.105)$ & $(0.113)$ \\
\hline \hline Observations & 5,275 & 2,714 & 2,561 \\
\hline \hline Standard errors in parentheses are clustered at the individual level \\
$* p<0.05, * * p<0.01, * * * p<0.001$ \\
Other covariates: education level, age group, income group, gender and partner \\
\hline
\end{tabular}

ated with changes in eligibility age expectations. The effect is non-negligible. One hundred additional newspaper articles that feature the Dutch acronym for old age social security ('AOW') in their title increase changes in expectations by 25 percent. Not only quantity but also the quality of news seems to matter; newspaper articles mentioning ' $\mathrm{AOW}$ ' in their title have an effect on expectation changes that is more than twice as large as the effect of those mentioning 'AOW' in the introduction. An additional probit-analysis of whether respondents changed their expectations (e.g. with at least 5 probability points) more often in periods of high publicity intensity showed no significant publicity coefficients. This indicates that the results in table 
5 are driven by larger expectation changes rather than by more respondents adapting their expectation answers.

\subsection{Publicity Reaction Coefficient}

The underlying expectations formation model that explains the estimation of the Publicity Reaction Coefficient (PRC) is laid out in Section 3 and will therefore not be repeated here. In this section I estimate the publicity reaction in old age social security expectations using the Dutch Pensionbarometer data. To obtain a first impression, Figure 6 depicts average squared expectation changes per survey week for the two different time horizons. As in Figures 4 and 5, the periods between the dotted lines are classified as low publicity periods (L) and the periods between the dashed lines as high publicity periods $(\mathrm{H})$. Although the extent to which respondents adapted their expectations does seem somewhat lower in the information-poor periods the difference is not overwhelming. This indicates that random shifts in expectation reports account for a substantial proportion of the variance in expectation changes; something that will be supported by the PRC evidence below.

Figure 6: Average squared change in probability assigned to later eligibility age per survey week. Low publicity periods between dotted lines (L). High publicity periods between dashed lines $(\mathrm{H})$.

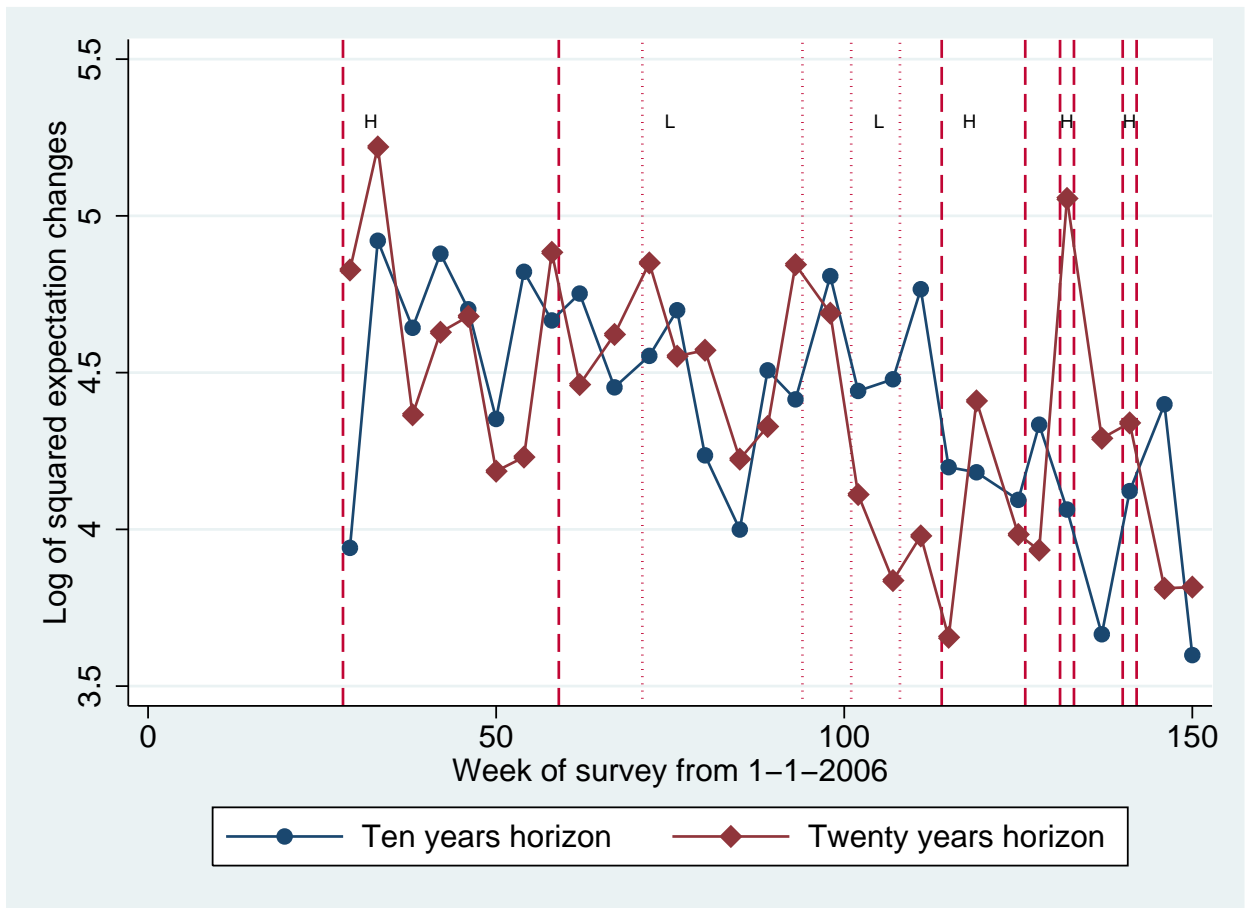

Table 6 then presents the estimates of the Publicity Reaction Coefficients 
for the total sample over the two different time horizons and for the four different expectation questions. To remind the reader: the Publicity Reaction Coefficient is defined as the ratio of the estimated systematic variance over the total variance of expectation changes. The estimated systematic variance equals the variance of expectation changes in high publicity periods $(H)$ minus this variance in low publicity periods $(L)$. The following equation, a repetition of Equation 1 in Section 3, displays how the Publicity Reaction Coefficient is constructed.

$$
P R C=\frac{E\left[\left(\Delta_{i, t^{H}} \tilde{y}^{t+z}\right)^{2}\right]-E\left[\left(\Delta_{i, t^{L}} \tilde{y}^{t+z}\right)^{2}\right]}{E\left[\left(\Delta_{i, t^{H}} \tilde{y}^{t+z}\right)^{2}\right]}
$$

The PRCs in the first column are estimated exploiting expectation changes in the high publicity and low publicity periods. To check the robustness of these results, the PRC estimates in the second column only use observations in very-high and very-low publicity periods. How high and low and very-high and very-low publicity periods are exactly defined is explained in Section 5. In Table A-2 in the appendix one finds the number of observations used per estimate divided into those from publicity-poor and those from publicity-rich periods. Throughout this section, PRC estimates are depicted in normal text when the involved error variance estimate is based on more than 50 observations. Italic text displays Publicity Reaction Coefficients that used error variance estimations based on in between 30 and 50 observations. Finally, a PRC is not displayed whenever less than 30 observations could be used to estimate the associated error variance.

All but three out of sixteen PRC estimates in Table 6 are positive,

Table 6: Publicity Reaction Coefficients for the total expectation changes sample

\begin{tabular}{|l|c|c|c|c|}
\hline & \multicolumn{2}{|c|}{$(\mathrm{I})$} & \multicolumn{2}{c|}{ (II) } \\
& \multicolumn{2}{|c|}{$\begin{array}{l}\text { Publicity-poor vs. } \\
\text { publicity-rich }\end{array}$} & $\begin{array}{l}\text { Publicity-very-poor vs. } \\
\text { publicity-very-rich }\end{array}$ \\
\hline & 10 years & 20 years & 10 years & 20 years \\
\hline \hline Prob. for higher age & $6.8 \%$ & $1.8 \%$ & $20.3 \% *$ & $-1.7 \%$ \\
& $(0.076)$ & $(0.090)$ & $(0.095)$ & $(0.134)$ \\
\hline Prob. for two year & $3.4 \%$ & $-2.2 \%$ & $16.1 \% *$ & $-4.5 \%$ \\
higher age & $(0.077)$ & $(0.082)$ & $(0.095)$ & $(0.129)$ \\
\hline Prob. for lower age & $13.5 \%$ & $19.5 \%$ & $20.5 \%$ & $9.0 \%$ \\
& $(0.164)$ & $(0.156)$ & $(0.211)$ & $(0.282)$ \\
\hline Prob. for two year & $10.9 \%$ & $30.5 \% *$ & $18.8 \%$ & $26.4 \%$ \\
lower age & $(0.216)$ & $(0.160)$ & $(0.282)$ & $(0.256)$ \\
\hline \hline
\end{tabular}


indicating that expectations do change more in periods with a larger publicity set. The publicity reaction is typically larger when the considered time horizon is shorter. Moreover, the probabilities that individuals assign to a lower eligibility age are more sensitive to publicity than the probabilities they assign to a higher eligibility age. For all subsamples however more than seventy percent of the variance in expectation changes was due to random shifts in expectations (as the highest significant PRC-estimate equals $30.5 \%)$. This is emphasized by the fact that only three PRCs are significantly different from zero.

The following tables report Publicity Reaction Coefficients that have

Table 7: PRCs for the probability of a higher eligibility age for five different age groups

\begin{tabular}{|l|c|c|c|c|}
\hline & \multicolumn{2}{|c|}{ (I) } & \multicolumn{2}{c|}{ (II) } \\
& $\begin{array}{l}\text { Publicity-poor vs. } \\
\text { publicity-rich }\end{array}$ & publicity-very-poor vs. \\
& 10 years & 20 years & 10 years & 20 years \\
\hline \hline Age 25-34 & $42.0 \% *$ & $-9.0 \%$ & $22.4 \%$ & $-73.7 \%$ \\
& $(0.162)$ & $(0.292)$ & $(0.335)$ & $(0.606)$ \\
\hline Age 35-44 & $-24.9 \%$ & $-11.2 \%$ & $-9.6 \%$ & $-92.5 \%$ \\
& $(0.224)$ & $(0.319)$ & $(0.310)$ & $(0.812)$ \\
\hline Age 45-54 & $15.6 \%$ & $20.1 \%$ & $33.6 \% *$ & $39.9 \% * *$ \\
& $(0.145)$ & $(0.144)$ & $(0.151)$ & $(0.158)$ \\
\hline Age 55-64 & $21.7 \%$ & $-6.5 \%$ & $30.9 \% *$ & $-9.2 \%$ \\
& $(0.133)$ & $(0.179)$ & $(0.157)$ & $(0.269)$ \\
\hline Age >64 & $-16.1 \%$ & $-8.1 \%$ & $4.3 \%$ & $2.1 \%$ \\
& $(0.190)$ & $(0.194)$ & $(0.235)$ & $(0.326)$ \\
\hline \hline Italic number: error variance based on 30-50 obs \\
Standard errors are bootstrapped and in parentheses \\
$* p<0.05, * * p<0.01, * * *<0.001$ \\
\hline
\end{tabular}

been estimated for different partitions of the total sample. To be relatively concise, results are only shown for the higher eligibility age expectations. The first three tables display PRCs for relevant demographic subgroups, while the last two tables focus on media consumption groups. It should be noted that the subgroup PRC estimates are conditional on the partition in the specified table only and not on other characteristics. This is because there are only a limited number of expectation changes in publicity-poor periods available to estimate the necessary error variance. Estimating the Publicity Reaction Coefficient for smaller subgroups would render these error variance estimates unreliable. The number of observations for each estimate in the subsequent tables can be found in Tables A-3, A-4, A-5, A-6 and A-7 in the appendix. 
Table 7 reports Publicity Reaction Coefficients for different age groups.

Table 8: PRCs for the probability of a higher eligibility age for five different education groups

\begin{tabular}{|c|c|c|c|c|}
\hline & \multicolumn{2}{|c|}{$\begin{array}{l}\quad \text { (I) } \\
\text { Publicity-poor vs. } \\
\text { publicity-rich }\end{array}$} & \multicolumn{2}{|c|}{$\begin{array}{l}\quad \text { (II) } \\
\text { Publicity-very-poor vs. } \\
\text { publicity-very-rich }\end{array}$} \\
\hline & 10 years & 20 years & 10 years & 20 years \\
\hline Primary & $\begin{array}{c}-49.1 \% \\
(0.608)\end{array}$ & $\begin{array}{c}27.9 \% \\
(0.264)\end{array}$ & $\begin{array}{l}\% \\
\text { (.) }\end{array}$ & $\begin{array}{l}\% \\
(.)\end{array}$ \\
\hline Vocational secondary & $\begin{array}{c}8.7 \% \\
(0.130)\end{array}$ & $\begin{array}{c}0.3 \% \\
(0.163)\end{array}$ & $\begin{array}{c}23.5 \% \\
(0.153)\end{array}$ & $\begin{array}{c}6.6 \% \\
(0.237)\end{array}$ \\
\hline General secondary & $\begin{array}{c}24.1 \% \\
(0.199)\end{array}$ & $\begin{array}{c}-3.1 \% \\
(0.249)\end{array}$ & $\begin{array}{l}40.9 \%^{*} \\
(0.199)\end{array}$ & $\begin{array}{c}-2.3 \% \\
(0.428)\end{array}$ \\
\hline Vocational tertiary & $\begin{array}{l}16.2 \% \\
(0.169)\end{array}$ & $\begin{array}{c}-1.2 \% \\
(0.229)\end{array}$ & $\begin{array}{c}5.5 \% \\
(0.302)\end{array}$ & $\begin{array}{l}-2.4 \% \\
(0.345)\end{array}$ \\
\hline Higher vocational & $\begin{array}{c}6.3 \% \\
(0.155)\end{array}$ & $\begin{array}{c}2.2 \% \\
(0.190)\end{array}$ & $\begin{array}{l}10.3 \% \\
(0.214)\end{array}$ & $\begin{array}{l}-4.9 \% \\
(0.302)\end{array}$ \\
\hline Academic education & $\begin{array}{l}-25.8 \% \\
(0.317)\end{array}$ & $\begin{array}{l}-30.7 \% \\
(0.357)\end{array}$ & $\begin{array}{c}6.4 \% \\
(0.329)\end{array}$ & $\begin{array}{c}-58.3 \% \\
(0.688) \\
\end{array}$ \\
\hline \multicolumn{5}{|c|}{$\begin{array}{l}\text { Italic number: error variance based on } 30-50 \text { obs } \\
\text { No number: error variance based on }<30 \text { obs } \\
\text { Standard errors are bootstrapped and in parentheses } \\
* p<0.05,{ }^{* *} p<0.01,{ }^{* * *} p<0.001\end{array}$} \\
\hline
\end{tabular}

Although it is hard to distinguish a clear pattern in the relationship between age and the reaction to publicity, the middle age category (between 45 and 54 ) does display the largest publicity reaction in three out of four columns. The PRC of the middle aged is moreover relatively large and significant when only the very-low and very-high publicity periods are taken into account. Interestingly, the subgroup with the lowest - even negative - publicity reaction are those individuals over the age of 64 that are already receiving old age social security. It can be argued that once someone receives a benefit she is no longer interested in news about the eligibility age as changes in this policy will not apply to her anymore. The same mechanism could explain that those in between 55 and 64 display a significant publicity reaction for a change within ten years (column II) but not for a change within twenty years.

Table 8 reports Publicity Reaction Coefficients for education subsamples. There does not appear to be a linear relationship between level of education and the degree to which a respondent reacts to publicity. Hardly any of the PRCs are significantly different from zero. What is striking however is that those respondents who managed to obtain a university degree 
Table 9: PRCs for the probability of a higher eligibility age for five different income groups

\begin{tabular}{|l|c|c|c|c|}
\hline & \multicolumn{2}{|c|}{ (I) } & \multicolumn{2}{c|}{ (II) } \\
& $\begin{array}{l}\text { Publicity-poor vs. } \\
\text { publicity-rich }\end{array}$ & $\begin{array}{l}\text { Publicity-very-poor vs. } \\
\text { publicity-very-rich }\end{array}$ \\
\hline & 10 years & 20 years & 10 years & 20 years \\
\hline \hline Low income & $1.0 \%$ & $27.6 \% *$ & $25.8 \%$ & $-0.4 \%$ \\
& $(0.175)$ & $(0.166)$ & $(0.177)$ & $(0.371)$ \\
\hline Lower middle & $19.2 \%$ & $-11.8 \%$ & $29.7 \% *$ & $-4.5 \%$ \\
income & $(0.156)$ & $(0.201)$ & $(0.194)$ & $(0.330)$ \\
\hline Middle income & $-9.0 \%$ & $3.3 \%$ & $-32.0 \%$ & $-0.1 \%$ \\
& $(0.184)$ & $(0.198)$ & $(0.304)$ & $(0.298)$ \\
\hline High middle & $33.7 \% *$ & $-5.7 \%$ & $37.9 \% *$ & $-1.3 \%$ \\
income & $(0.117)$ & $(0.235)$ & $(0.171)$ & $(0.336)$ \\
\hline High income & $-2.7 \%$ & $-17.8 \%$ & $10.3 \%$ & $-23.5 \%$ \\
\multicolumn{7}{|l|}{$(0.192)$} & $(0.226)$ & $(0.277)$ & $(0.355)$ \\
\hline \hline Italic number: error variance based on 30-50 obs \\
Standard errors are bootstrapped and in parentheses \\
$* p<0.05, * * p<0.01, * * * p<0.001$ \\
\hline
\end{tabular}

do not respond to publicity at all; their negative PRCs even indicate that they change their expectations more in publicity-poor than in publicity-rich periods. Perhaps high educated individuals have such high-quality initial expectations that information disseminated through the media does not induce them to change their policy forecasts.

The sample is stratified in five income classes for the estimation of the Publicity Reaction Coefficients in Table 9. The ranking of income subgroups in terms of PRC estimates is rather different over the four columns. However, the high middle income category displayed the highest publicity reaction in both ten years-columns, the middle income category displayed the lowest publicity reaction in these columns and the highest income category displayed the lowest publicity reaction in both twenty years-columns. These differences between adjacent groups are surprising and suggest that several opposing factors influence the relationship between income and the publicity reaction. A possible explanation for the low PRCs of the highest income group could be that the future of old age social security does not interest them as they foresee enough alternative income sources.

Table 10 reports Publicity Reaction Coefficients for media consumption and self-reported political awareness subgroups. While focusing on newspaper consumption, what catches the attention is that those who read the newspaper once a week or less have the highest publicity reaction. This is the case for all estimates, except for the ten years-horizon in the publicity- 
Table 10: PRCs for different media consumption groups

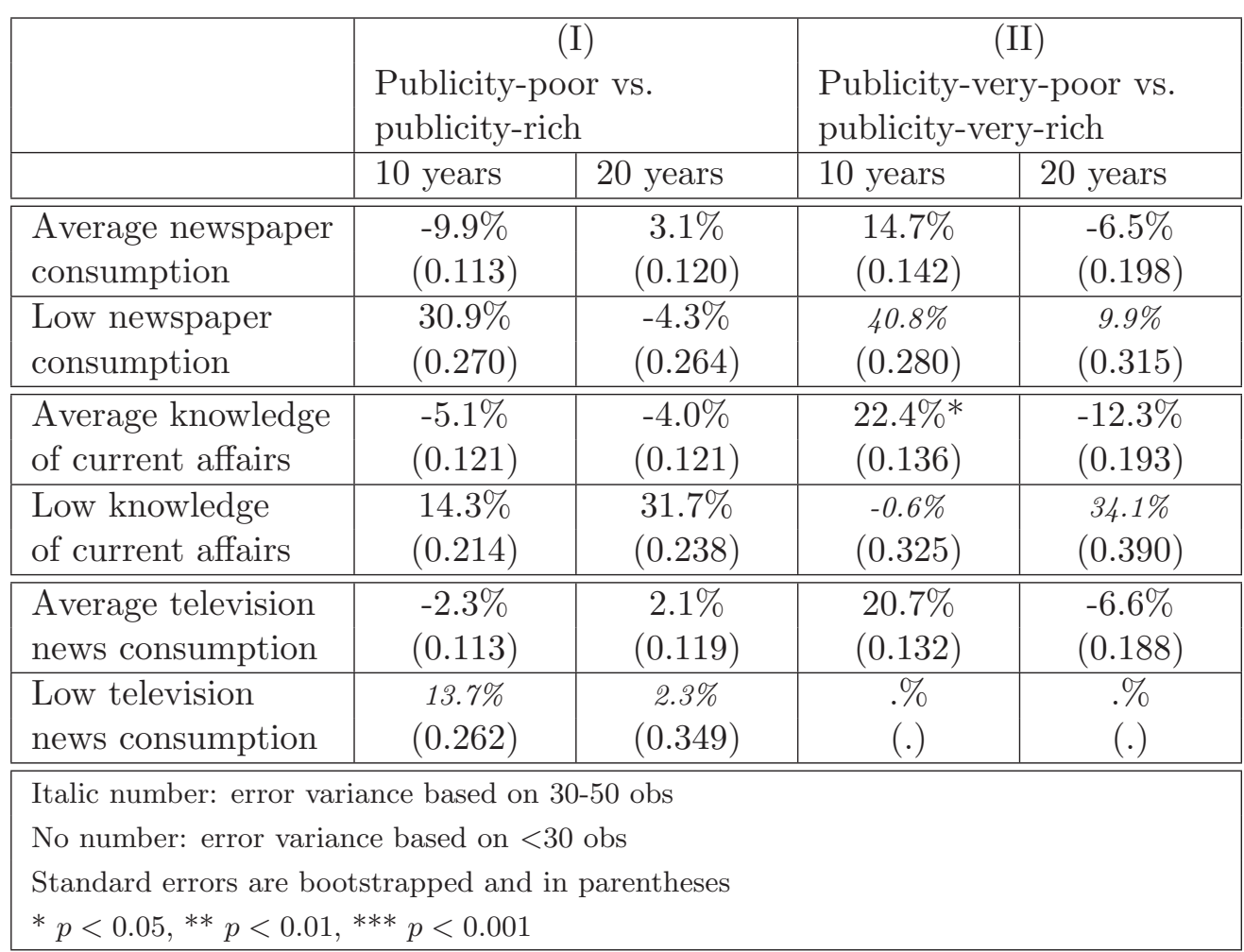

poor versus the publicity-rich comparison. A similar picture emerges from the results on individuals' knowledge of current affairs in Dutch politics. Individuals who themselves report that their knowledge is lower than that of the average Dutchmen, display higher Publicity Reaction Coefficients. This thus means that ill-informed individuals do pick up on some of the released publicity on the relevant topic and change their expectations accordingly. At first, these results seem counterintuitive. If low media consumption is however correlated with low initial knowledge of old age social security, one can imagine that publicity should induce more changes in the expectations of the low informed group. The television news results are in the same direction, but very unprecise as the number of respondents who report low television news consumption is low.

Finally, Table 11 shows PRC estimates for a partition of the dataset into what type of newspaper one most often reads. Four specific categories are selected: those who obtain most information from free newspapers, those who most often read 'de Telegraaf' - a populist/ conservative newspaper, those who most often read 'de Volkskrant' - a progressive newspaper and those who most often read 'NRC Handelsblad' - a liberal newspaper. It turns out that those who only read free newspapers and those who often read the 
Table 11: PRCs for the probability of a higher eligibility age for five different newspaper readership groups

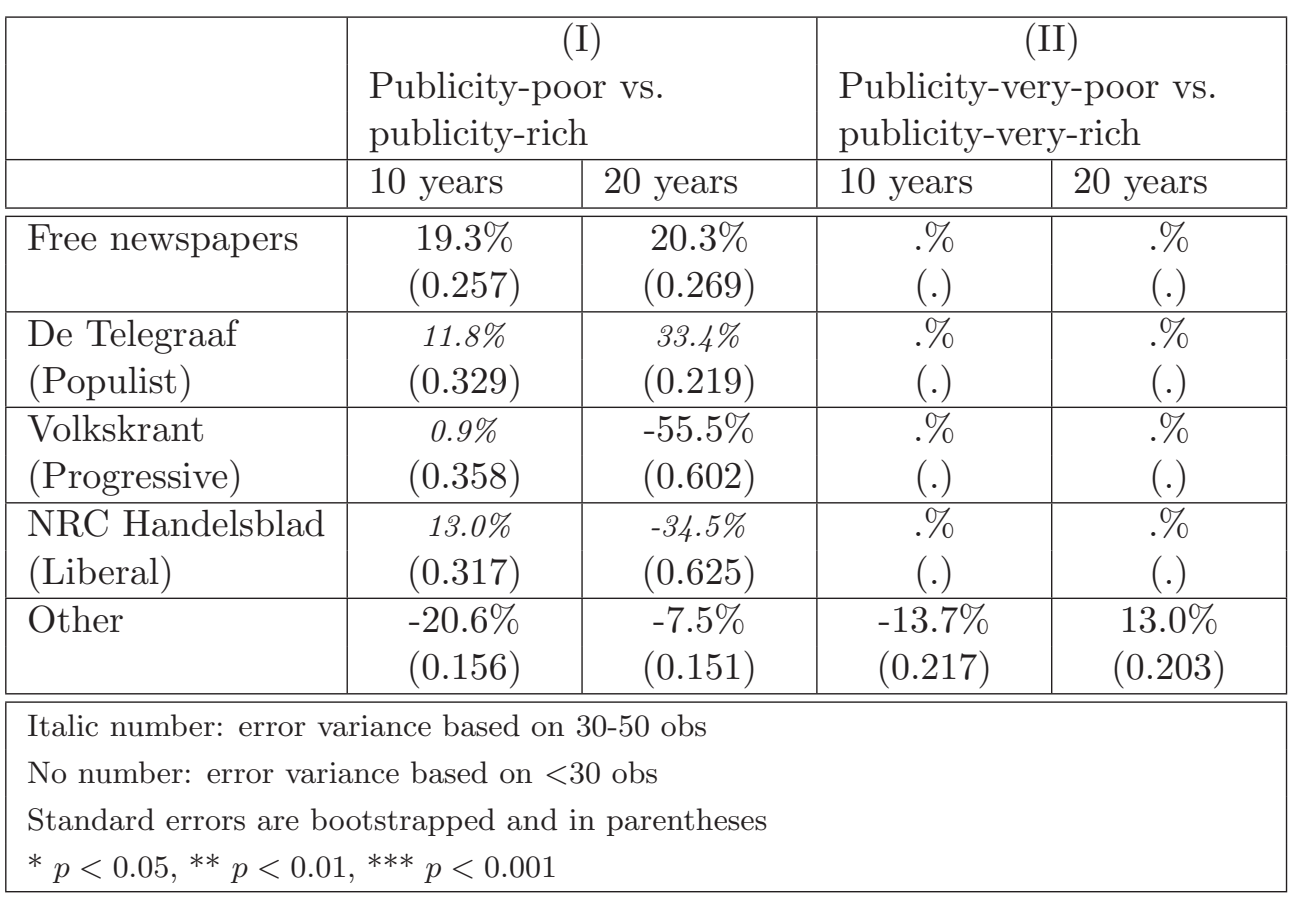

populist newspaper have the highest publicity reactions. This could be because of the specific wording in and content of the articles, but also because the individuals that typically read these newspapers have low-quality initial expectations. Those who read the progressive newspaper do seem not very influenceable by the media in terms of their expectations. Respondents who are in the 'other newspaper' category, which includes regional and smaller national newspapers, display the smallest publicity reaction.

All in all, the presented Publicity Reaction Coefficients for the different demographic and media consumption subgroups paint an interesting picture. Three groups are identified that do not adapt their expectations more strongly in high publicity-periods: those over the age of 64 , those with a university degree and the highest income group. The middle aged respond relatively heavily to publicity in terms of their expectations, just like those who do not often read a newspaper and those who read free newspapers or 'de Telegraaf'. Also the respondents that indicate themselves that they know little about Dutch politics display a higher publicity reaction. Since the PRC estimates in this section are only conditional on the characteristic presented in each table, it it unclear what the most important determinants of differential publicity reaction are. More research will be needed to uncover this.

Three explanations of these results come to mind that probably all ex- 
plain some part of reality. All three involve the publicity set $\Theta_{t}$ that individuals use as an input in their expectations formation process. First, generally less-informed groups are more susceptible to repetitions of old news in the media, $\Phi_{t}$. The quality of the initial expectations of those with a university degree and the highest income groups is probably higher than the quality of expectations of, say, those who do not often read a newspaper. If the publicity set contains mostly 'old' news those who did not pay enough attention to the news before, should respond to these publicity items by shifting their expectations up or down, depending on which old news elements they absorbed over the last period. A second explanation only concerns the Publicity Reaction Coefficient estimates of which type of newspaper the respondent most often reads. As mentioned above, it is possible that the type and tone of news that is published in free and more populist newspapers is such that it leads to higher expectation changes by its readers. Third, as mentioned before, some groups have lower stakes in the future of the old age social security eligibility age so that they will hardly pay attention to the publicity set $\Theta_{t}$. Those already receiving a benefit and those who are financially well-off probably do not suffer much when the eligibility age goes up and hence will ignore news on the matter.

\subsection{Variance in expectation change error terms explained}

As explained in Section 3.4, a side product of the estimation of the Publicity Reaction Coefficients is that one can analyze individuals' reporting errors by investigating their expectation changes in the publicity-poor periods. Table 12 presents estimation results for regressing the log of squared expectation changes in the low publicity periods as defined in Section 5 on several demographic characteristics. Changes in expectations are assumed to be drawings from the reporting error variance here and the presented regressions thus capture the factors that influence heteroscedasticity. The regression coefficients will explain which groups are more likely to provide erroneous expectation answers.

The age group dummies turn out to be among the few significant covariates in explaining how error-prone individuals are. Typically, the younger the respondent the lower the error variance is. This means that especially those over 64 are more inclined to randomly shift their expectations up and down, even if no publicity forces them to do so. In the twenty years-horizon regression, the group of people between 35 and 44 years old is the only that is significantly less error-prone than the elderly. Income also matters significantly in explaining mistakes in the second column. Those with lower middle incomes and middle incomes have higher estimated error variances. In general, the explanatory power of these regressions is low, indicating that there is large individual heterogeneity in the prediction error variances. 
Table 12: Coefficients and standard errors of OLS models. Dependent variable: logarithm of squared expectation changes in publicity-poor periods.

\begin{tabular}{lcccc}
\hline \hline & \multicolumn{2}{c}{$(1)$} & \multicolumn{2}{c}{$(2)$} \\
& Coef. & Sears & Coef. & S.e. \\
\hline Age 25-34 & $-1.530^{* * *}$ & $(0.390)$ & -0.217 & $(0.420)$ \\
Age 35-44 & -0.492 & $(0.364)$ & $-0.701^{*}$ & $(0.409)$ \\
Age 45-54 & $-0.718^{*}$ & $(0.331)$ & -0.435 & $(0.368)$ \\
Age 55-64 & $-0.706^{*}$ & $(0.337)$ & 0.300 & $(0.364)$ \\
Vocational secondary & -0.248 & $(0.503)$ & -0.362 & $(0.528)$ \\
General secondary & 0.210 & $(0.535)$ & -0.687 & $(0.620)$ \\
Vocational tertiary & -0.464 & $(0.532)$ & -0.627 & $(0.555)$ \\
Higher vocational & -0.208 & $(0.521)$ & -0.841 & $(0.562)$ \\
Academic education & -0.184 & $(0.609)$ & -0.291 & $(0.638)$ \\
Low middle income & 0.001 & $(0.365)$ & $0.956^{* *}$ & $(0.412)$ \\
Middle income & 0.106 & $(0.376)$ & $0.929^{*}$ & $(0.431)$ \\
High middle income & -0.329 & $(0.377)$ & 0.517 & $(0.464)$ \\
High income & -0.400 & $(0.446)$ & 0.549 & $(0.552)$ \\
Dummy female & -0.095 & $(0.259)$ & 0.228 & $(0.292)$ \\
Dummy partner & 0.176 & $(0.273)$ & 0.069 & $(0.266)$ \\
\hline Observations & 740 & & 741 & \\
Individuals & 554 & & 559 & \\
$R^{2}$ & $3.4 \%$ & & $3.1 \%$ & \\
\hline \hline
\end{tabular}

Standard errors are corrected for clustering at the individual level

${ }^{*} p<0.05,{ }^{* *} p<0.01,{ }^{* * *} p<0.001$

Base categories: primary education, age $>64$, low income 


\section{Conclusion}

As empirical evidence is accumulating that subjective expectations influence economic decision-making and that these expectations are sometimes biased, it becomes policy-relevant to know how to influence individuals' expectations. It is likely in this respect that information in the media affects how people feel about the future. This paper sheds light on the role of public information dissemination, or publicity, in a real-life expectations formation process. More specifically: I estimate the degree to which different demographic and media consumption groups adapt their expectations to publicity about the relevant random variable.

To examine demographic differences in the publicity reaction, one needs data of an expectation on which private information has no influence in order to circumvent identification problems. I therefore use the Pensionbarometer, a unique monthly dataset of expectations on the Dutch old age social security eligibility age. As the relevant media attention differed substantially over the survey period, I am able to estimate the proportion of the variance in the eligibility age expectation changes that can be attributed to publicity (the Publicity Reaction Coefficient - PRC) without making strong assumptions on the expectations formation process.

My findings are in line with other empirical papers that suggest media intensity affects the precision and updating of inflation expectations (Carroll, 2003, and Lamla and Lein, 2008). For the total population, the publicity reaction in eligibility age expectations is estimated to be in between zero and thirty percent. Rather than publicity, random shifts thus explain the majority of the variance in changes in eligibility age expectations, with especially older individuals being more imprecise in their expectation reports. The differences in the publicity reaction among subgroups are considerable however. I find that middle-aged, those who infrequently read newspaper and those who know little about Dutch politics have a relatively high publicity reaction. This can be understood if the majority of newspaper articles about old age social security contains 'old news' rather than real information revelations. It is after all likely that those with lower quality initial expectations adapt their expectations more whenever already available information is repeated in the media. Also those who report to obtain most of their news content from either free or a populist newspaper ('De Telegraaf') change their expectations more severely in high-publicity periods. The wording in and content of these newspapers could explain this observation. Moreover, I find that those over the age of 64 and high income individuals do not adapt their expectations more often in publicity-high periods. It seems as if those with low stakes in the future of the old age social security eligibility age pay little attention to publicity on the matter.

Provided that the explanations that I propose for my PRC results are valid, policy-makers could learn the following about publicity and expec- 
tations formation. On the one hand, those who have low quality initial expectations are easily influenced by whatever appears on the subject in newspapers and on television. If policy-makers would like to influence the expectations of the weaker informed group it would be wise to often repeat high-quality information in the media so that eventually even they hear the news. On the other hand, those who feel they have little to do with the expectation at hand are hard to influence by public information dissemination, as they will hardly pay attention to the news. This is fine when the disinterest is justified, but rather problematic when it is not.

\section{References}

Arrow, K. and Nerlove, M.: 1958, A Note on Expectations and Stability, Econometrica 26(2), 297-305.

Bernanke, B.: 2007, Inflation Expectations and Inflation Forecasting, Speech, Monetary Workshop of the NBER Summer Institute.

Bernheim, B. and Levin, L.: 1989, Social Security and Personal Saving: An Analysis of Expectations, American Economic Review 79(2), 97-102.

Branch, W.: 2004, The Theory of Rationally Heterogeneous Expectations: Evidence from Survey Data on Inflation Expectations, Economic Journal 114, 592-621.

Carman, K. and Kooreman, P.: 2007, Flu Shots, Mammograms and the Statistical Value of Life, Netspar working paper, Tilburg University.

Carroll, C. D.: 2003, Macroeconomic Expectations of Households and Professional Forecasters, Quarterly Journal of Economics 118(1), 269-298.

Caskey, J.: 1985, Modelling the Formation of Price Expectations: A Bayesian Approach, American Economic Review 75(4), 768-776.

De Bondt, W. and Thaler, R.: 1990, Do Security Analysts Overreact?, American Economic Review 80(2), 52-57.

Dominitz, J., Manski, C. and Heinz, J.: 2002, Social Security Expectations and Retirement Savings Decisions, JCPR Working Papers 273, Northwestern University/University of Chicago Center for Poverty Research.

Dominitz, J., Manski, C. and Heinz, J.: 2003, "Will Social Security be there for you?": How Americans Perceive their Benefits, NBER Working Papers 9798.

Figlewski, S. and Wachtel, P.: 1981, The Formation of Inflationary Expectations, Review of Economics and Statistics 63(1), 1-10. 
Gramlich, E.: 1983, Models of Inflation Expectations Formation: A Comparison of Household and Economist Forecasts, Journal of Money, Credit and Banking 15(2), 155-173.

Ito, T.: 1990, Foreign Exchange Rate Expectations: Micro Survey Data, American Economic Review 80(3), 434-449.

Jonung, L.: 1981, Perceived and Expected Rates of Inflation in Sweden, American Economic Review 71(5), 961-968.

Keane, M. and Runkle, D.: 1990, Testing the Rationality of Price forecasts: New Evidence from Panel Data, American Economic Review 80(4), 714-735.

Lamla, M. and Lein, S.: 2008, The Role of Media for Consumers' Inflation Expectation Formation, KOF Working Papers 201, KOF Swiss Economic Institute.

Lochner, L.: 2007, Individual Perceptions of the Criminal Justice System, American Economic Review 97(1), 444-460.

Mankiw, N. G. and Reis, R.: 2002, Sticky Information Versus Sticky Prices: A Proposal to Replace the New Keynesian Phillips Curve, Quarterly Journal of Economics 117(4), 1295-1328.

Mankiw, N. G., Reis, R. and Wolfers, J.: 2003, Disagreement about Inflation Expectations, NBER Working Papers 9796.

Manski, C. F.: 2004, Measuring Expectations, Econometrica 72(5), 13291376 .

Muth, J.: 1961, Rational Expectations and the Theory of Price Movements, Econometrica 29(3), 315-335.

Souleles, N.: 2004, Expectations, Heterogeneous Forecast Errors, and Consumption: Micro Evidence from the Michigan Consumer Sentiment Surveys, Journal of Money, Credit, and Banking 36(1), 39-72.

Stephens, M.: 2004, Job Loss Expectations, Realizations, and Household Consumption Behavior, Review of Economics and Statistics 86(1), 253269.

Tversky, A. and Kahneman, D.: 1974, Judgment under uncertainty: Heuristics and biases, Science 185(4157), $1124-1131$.

Van der Wiel, K.: 2008, Preparing for Policy Changes: Social Security Expectations and Pension Scheme Participation, IZA Working Paper 3623. 
Viscusi, W. K. and Hakes, J.: 2008, Risk Beliefs and Smoking Behavior, Economic Inquiry 46(1), 45-59.

\section{A Figures}

Figure A-1: Histogram of probabilities assigned to higher eligibility age within twenty years.

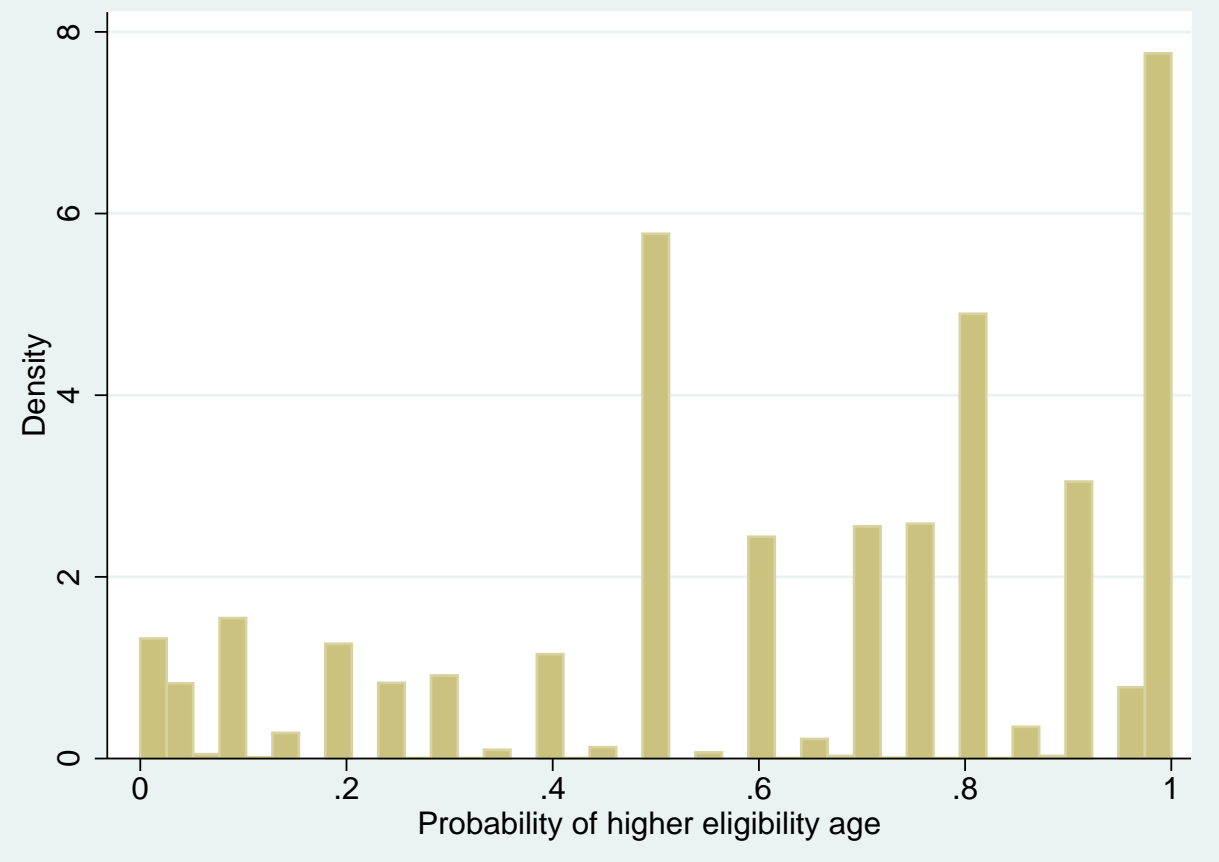


Figure A-2: Interquartile range for probability assigned to higher eligibility age within twenty years (week 1-52: 2006, week 53-75: 2007, week 105-157: 2008).

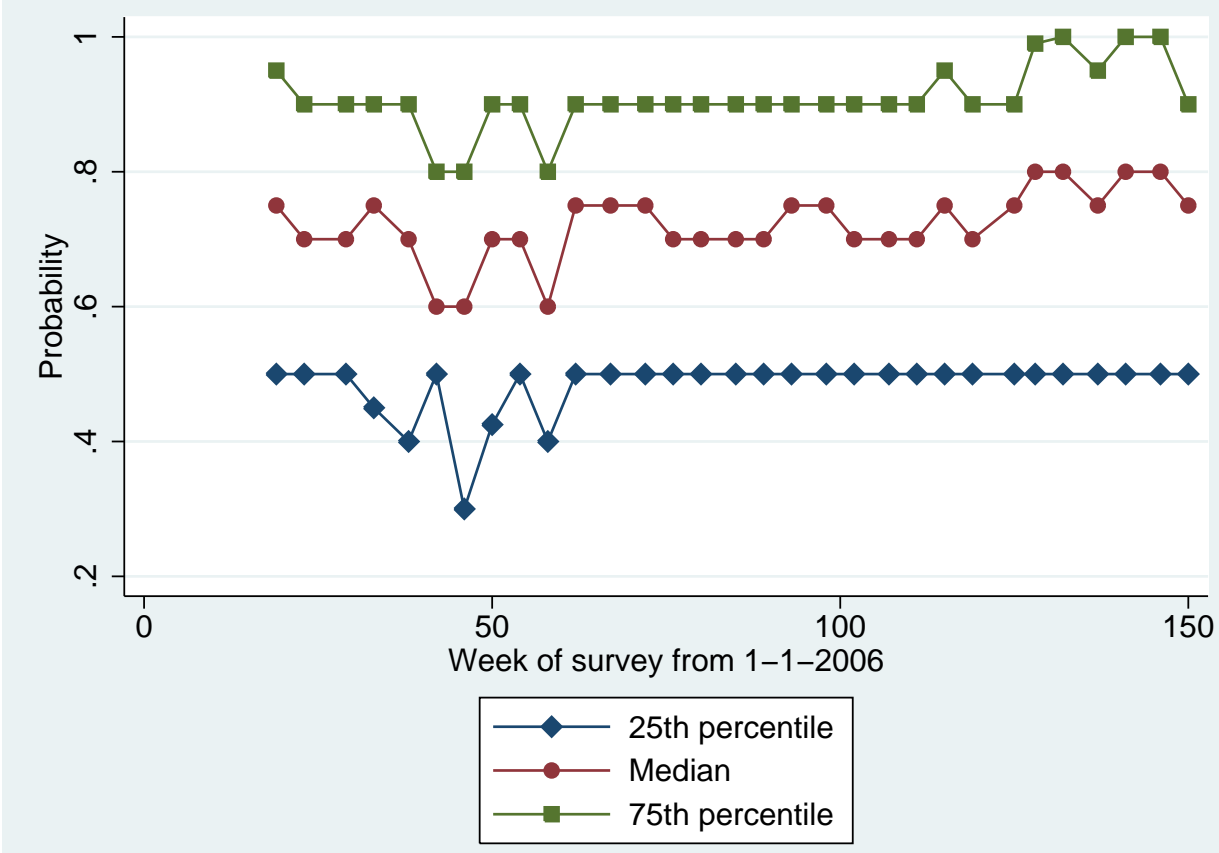

\section{B Tables}


Table A-1: Overview of classification of survey weeks

\begin{tabular}{|c|c|c|c|c|c|c|c|}
\hline Week & Year & $\begin{array}{l}\text { End sur- } \\
\text { vey week }\end{array}$ & $\begin{array}{l}\text { Start } \\
\text { media } \\
\text { count }\end{array}$ & $\begin{array}{l}\text { Low } \\
\text { publicity }\end{array}$ & $\begin{array}{l}\text { Very low } \\
\text { publicity }\end{array}$ & $\begin{array}{l}\text { High } \\
\text { publicity }\end{array}$ & $\begin{array}{l}\text { Very } \\
\text { high } \\
\text { publicity }\end{array}$ \\
\hline 19 & 2006 & 13-mei & & No & No & No & No \\
\hline 23 & 2006 & 10-jun & & No & No & No & No \\
\hline 29 & 2006 & 22-jul & 2-apr & No & No & Yes & Yes \\
\hline 33 & 2006 & 19-aug & 14-mei & No & No & Yes & Yes \\
\hline 38 & 2006 & 23-sep & 11-jun & No & No & Yes & Yes \\
\hline 42 & 2006 & 21-okt & 23-jul & No & No & Yes & Yes \\
\hline 46 & 2006 & 18-nov & 20-aug & No & No & Yes & Yes \\
\hline 50 & 2006 & 16-dec & 24-sep & No & No & Yes & Yes \\
\hline 54 & 2007 & 13-jan & 22 -okt & No & No & Yes & No \\
\hline 58 & 2007 & $10-f e b$ & 19-nov & No & No & Yes & No \\
\hline 62 & 2007 & 9-mrt & 17-dec & No & No & No & No \\
\hline 67 & 2007 & 13-apr & 14-jan & No & No & No & No \\
\hline 72 & 2007 & 18-mei & 11-feb & Yes & No & No & No \\
\hline 76 & 2007 & 15-jun & 10-mrt & Yes & Yes & No & No \\
\hline 80 & 2007 & 13 -jul & 14-apr & Yes & No & No & No \\
\hline 85 & 2007 & 17-aug & 19-mei & Yes & Yes & No & No \\
\hline 89 & 2007 & 14-sep & 16-jun & Yes & Yes & No & No \\
\hline 93 & 2007 & 12-okt & 14-jul & Yes & No & No & No \\
\hline 98 & 2007 & 16-nov & 18-aug & No & No & No & No \\
\hline 102 & 2007 & 14-dec & 15 -sep & Yes & No & No & No \\
\hline 107 & 2008 & 19-jan & 13-okt & Yes & No & No & No \\
\hline 111 & 2008 & 16 -feb & 17-nov & No & No & No & No \\
\hline 115 & 2008 & 15-mrt & 15 -dec & No & No & Yes & Yes \\
\hline 119 & 2008 & 12-apr & 20-jan & No & No & Yes & No \\
\hline 125 & 2008 & 24-mei & 17 -feb & No & No & Yes & No \\
\hline 128 & 2008 & 14-jun & 16-mrt & No & No & No & No \\
\hline 132 & 2008 & 12-jul & 13-apr & No & No & No & No \\
\hline 137 & 2008 & 16-aug & 25-mei & No & No & No & No \\
\hline 141 & 2008 & 13 -sep & 15-jun & No & No & No & No \\
\hline 146 & 2008 & 18-okt & 13-jul & No & No & No & No \\
\hline 150 & 2008 & 15 -nov & 17-aug & No & No & No & No \\
\hline
\end{tabular}


Table A-2: Number of observations in estimation of Publicity Reaction Coefficients for the total expectation changes sample

\begin{tabular}{|l|l|c|c|c|}
\hline & \multicolumn{2}{|c|}{ (I) } & \multicolumn{2}{c|}{ (II) } \\
& $\begin{array}{l}\text { Publicity-poor vs. } \\
\text { publicity-rich }\end{array}$ & $\begin{array}{l}\text { Publicity-very-poor vs. } \\
\text { publicity-very-rich }\end{array}$ \\
\hline & 10 years & 20 years & 10 years & 20 years \\
\hline \hline Prob. for higher age & 1,233 & 1,155 & 685 & 633 \\
& $(744)$ & $(742)$ & $(302)$ & $(273)$ \\
\hline Prob. for two year & 1,232 & 1,154 & 684 & 632 \\
higher age & $(744)$ & $(736)$ & $(302)$ & $(272)$ \\
\hline Prob. for lower age & 1,232 & 1,152 & 684 & 631 \\
& $(742)$ & $(734)$ & $(301)$ & $(271)$ \\
\hline Prob. for two year & 1,231 & 1,152 & 683 & 631 \\
lower age & $(741)$ & $(733)$ & $(301)$ & $(270)$ \\
\hline \hline \multicolumn{2}{|l|}{ Observations in publicity-poor periods in parentheses } \\
\hline
\end{tabular}

Table A-3: Number of observations in estimation of PRCs for the probability of a higher eligibility age for five different age groups

\begin{tabular}{|l|c|c|c|c|}
\hline & \multicolumn{2}{|c|}{ (I) } & \multicolumn{2}{c|}{ (II) } \\
& $\begin{array}{l}\text { Publicity-poor vs. } \\
\text { publicity-rich }\end{array}$ & $\begin{array}{l}\text { Publicity-very-poor vs. } \\
\text { publicity-very-rich }\end{array}$ \\
\hline & 10 years & 20 years & 10 years & 20 years \\
\hline \hline Age 25-34 & 166 & 150 & 95 & 83 \\
& $(103)$ & $(97)$ & $(48)$ & $(34)$ \\
\hline Age 35-44 & 231 & 186 & 133 & 98 \\
& $(116)$ & $(117)$ & $(38)$ & $(38)$ \\
\hline Age 45-54 & 304 & 268 & 166 & 155 \\
& $(177)$ & $(198)$ & $(81)$ & $(86)$ \\
\hline Age 55-64 & 279 & 281 & 146 & 150 \\
& $(185)$ & $(173)$ & $(71)$ & $(59)$ \\
\hline Age $>64$ & 253 & 270 & 145 & 147 \\
& $(163)$ & $(157)$ & $(64)$ & $(56)$ \\
\hline \hline
\end{tabular}


Table A-4: Number of observations in estimation of PRCs for the probability of a higher eligibility age for five different education groups

\begin{tabular}{|l|c|c|c|c|}
\hline & \multicolumn{2}{|c|}{ (I) } & \multicolumn{2}{c|}{ (II) } \\
& $\begin{array}{l}\text { Publicity-poor vs. } \\
\text { publicity-rich }\end{array}$ & $\begin{array}{l}\text { Publicity-very-poor vs. } \\
\text { publicity-very-rich }\end{array}$ \\
\hline & 10 years & 20 years & 10 years & 20 years \\
\hline \hline Primary & 53 & 68 & 31 & 37 \\
& $(43)$ & $(47)$ & $(18)$ & $(19)$ \\
\hline Vocational secondary & 341 & 312 & 196 & 174 \\
& $(232)$ & $(207)$ & $(89)$ & $(78)$ \\
\hline General secondary & 127 & 151 & 71 & 84 \\
& $(83)$ & $(85)$ & $(40)$ & $(22)$ \\
\hline Vocational tertiary & 258 & 233 & 136 & 135 \\
& $(146)$ & $(143)$ & $(48)$ & $(51)$ \\
\hline Higher vocational & 299 & 264 & 171 & 139 \\
& $(156)$ & $(180)$ & $(77)$ & $(71)$ \\
\hline Academic education & 155 & 127 & 80 & 64 \\
& $(84)$ & $(80)$ & $(30)$ & $(32)$ \\
\hline \hline
\end{tabular}

Table A-5: Number of observations in estimation of PRCs for the probability of a higher eligibility age for five different income groups

\begin{tabular}{|l|c|c|c|c|}
\hline & \multicolumn{2}{|c|}{ (I) } & \multicolumn{2}{c|}{ (II) } \\
& Publicity-poor vs. & \multicolumn{2}{c|}{$\begin{array}{l}\text { Publicity-very-poor vs. } \\
\text { publicity-very-rich }\end{array}$} \\
\hline & 10 years & 20 years & 10 years & 20 years \\
\hline \hline Low income & 252 & 204 & 149 & 118 \\
& $(150)$ & $(124)$ & $(61)$ & $(43)$ \\
\hline Lower middle & 223 & 255 & 138 & 131 \\
income & $(151)$ & $(142)$ & $(66)$ & $(44)$ \\
\hline Middle income & 244 & 207 & 133 & 119 \\
& $(159)$ & $(178)$ & $(56)$ & $(62)$ \\
\hline Higher middle & 256 & 224 & 134 & 125 \\
income & $(130)$ & $(161)$ & $(62)$ & $(68)$ \\
\hline High income & 244 & 256 & 127 & 136 \\
& $(150)$ & $(136)$ & $(57)$ & $(56)$ \\
\hline \hline
\end{tabular}


Table A-6: Number of observations in estimation of PRCs for the probability of a higher eligibility age for newspaper consumption and self-reported political awareness

\begin{tabular}{|l|c|c|c|c|}
\hline & \multicolumn{2}{|c|}{ (I) } & \multicolumn{2}{c|}{ (II) } \\
& $\begin{array}{l}\text { Publicity-poor vs. } \\
\text { publicity-rich }\end{array}$ & $\begin{array}{l}\text { Publicity-very-poor vs. } \\
\text { publicity-very-rich }\end{array}$ \\
\hline & 10 years & 20 years & 10 years & 20 years \\
\hline \hline Average newspaper & 676 & 627 & 355 & 313 \\
consumption & $(397)$ & $(421)$ & $(153)$ & $(147)$ \\
\hline Low newspaper & 119 & 128 & 58 & 67 \\
consumption & $(55)$ & $(78)$ & $(18)$ & $(31)$ \\
\hline \hline Average television & 712 & 681 & 375 & 340 \\
news consumption & $(408)$ & $(450)$ & $(151)$ & $(162)$ \\
\hline Low television & 83 & 74 & 38 & 40 \\
news consumption & $(44)$ & $(49)$ & $(20)$ & $(16)$ \\
\hline \hline Average informedness & 662 & 640 & 340 & 328 \\
& $(384)$ & $(425)$ & $(145)$ & $(151)$ \\
\hline Low informedness & 133 & 115 & 73 & 52 \\
& $(68)$ & $(74)$ & $(26)$ & $(27)$ \\
\hline \hline
\end{tabular}

Table A-7: Number of observations in estimation of PRCs for the probability of a higher eligibility age for five different newspaper readership groups

\begin{tabular}{|c|c|c|c|c|}
\hline & \multicolumn{2}{|c|}{\begin{tabular}{l}
\multicolumn{1}{c}{$(\mathrm{I})$} \\
Publicity-poor vs. \\
publicity-rich
\end{tabular}} & \multicolumn{2}{|c|}{$\begin{array}{l}\text { (II) } \\
\text { Publicity-very-poor vs. } \\
\text { publicity-very-rich }\end{array}$} \\
\hline & 10 years & 20 years & 10 years & 20 years \\
\hline Free newspapers & $\begin{array}{c}80 \\
(55)\end{array}$ & $\begin{array}{c}91 \\
(56)\end{array}$ & $\begin{array}{l}49 \\
(20)\end{array}$ & $\begin{array}{c}53 \\
(28)\end{array}$ \\
\hline $\begin{array}{l}\text { De Telegraaf } \\
\text { (Populist) }\end{array}$ & $\begin{array}{l}89 \\
(47)\end{array}$ & $\begin{array}{c}86 \\
(49)\end{array}$ & $\begin{array}{c}40 \\
(21)\end{array}$ & $\begin{array}{c}48 \\
(15)\end{array}$ \\
\hline $\begin{array}{l}\text { De Volkskrant } \\
\text { (Progressive) }\end{array}$ & $\begin{array}{c}78 \\
(46)\end{array}$ & $\begin{array}{c}65 \\
(59)\end{array}$ & $\begin{array}{c}37 \\
(15)\end{array}$ & $\begin{array}{c}28 \\
(24)\end{array}$ \\
\hline $\begin{array}{l}\text { NRC Handelsblad } \\
\text { (Liberal) }\end{array}$ & $\begin{array}{c}50 \\
(40)\end{array}$ & $\begin{array}{l}57 \\
(31)\end{array}$ & $\begin{array}{c}28 \\
(18)\end{array}$ & $\begin{array}{l}26 \\
(7)\end{array}$ \\
\hline Other & $\begin{array}{r}459 \\
(241)\end{array}$ & $\begin{array}{c}405 \\
(280)\end{array}$ & $\begin{array}{l}243 \\
(90)\end{array}$ & $\begin{array}{l}196 \\
(94)\end{array}$ \\
\hline
\end{tabular}

